2012-08-06

\title{
Study on the Fracture Toughness of Friction Stir Welded API X80
}

Allan M. Tribe

Brigham Young University - Provo

Follow this and additional works at: https://scholarsarchive.byu.edu/etd

Part of the Mechanical Engineering Commons

\section{BYU ScholarsArchive Citation}

Tribe, Allan M., "Study on the Fracture Toughness of Friction Stir Welded API X80" (2012). Theses and Dissertations. 3740.

https://scholarsarchive.byu.edu/etd/3740

This Thesis is brought to you for free and open access by BYU ScholarsArchive. It has been accepted for inclusion in Theses and Dissertations by an authorized administrator of BYU ScholarsArchive. For more information, please contact scholarsarchive@byu.edu, ellen_amatangelo@byu.edu. 
Study on the Fracture Toughness of Friction Stir Welded API X80

Allan Tribe

A thesis submitted to the faculty of

Brigham Young University

in partial fulfillment of the requirements for the degree of

Master of Science

Tracy W. Nelson, Chair

Carl D. Sorensen

Mike P. Miles

Department of Mechanical Engineering

Brigham Young University

December 2012

Copyright (C) 2012 Allan Tribe

All Rights Reserved 


\author{
ABSTRACT \\ Study on the Fracture Toughness of Friction Stir Welded API X80 \\ Allan Tribe \\ Department of Mechanical Engineering, BYU \\ Master of Science
}

High strength low alloy (HSLA) steels have been developed to simultaneously have high yield strength and high fracture toughness. However, in practical applications steel must be welded. Traditional arc welding has proven detrimental to the fracture toughness of HSLA steels. Friction stir welding has recently shown mixed results in welding HSLA steels. The range of welding parameters used in these recent studies however has been very limited. With only a few welding parameters tested, the effect of spindle speed, travel speed, and heat input on the fracture toughness of friction stir welded HSLA steel remains unknown.

To understand how the friction stir welding process parameters affect fracture toughness, double sided welds in API X80 were performed and analyzed. Results show that at room temperature friction stir welded API X80 exceeded industry minimum fracture toughness requirements in both the API Standard 1104 and DNV-OS-F101 by $143 \%$ and $62 \%$, respectively. The process parameters of spindle speed and HI have been shown to effectively control the fracture toughness of the stir zone. Relationships have been established that show that fracture toughness increased by $85 \%$ when spindle speed decreased by $59 \%$ and heat input decreased by $46 \%$.

Keywords: Allan Tribe, friction stir welding, HSLA, steel, API X80, fracture toughness, CTOD, J1c, microstructure, polygonal ferrite, bainite, lath, packet, heat input, hard zone, hardness 


\section{ACKNOWLEDGEMENTS}

I would like to thank my wife and children for supporting me and encouraging me throughout the research and writing of this thesis. Secondly, much thanks is due to Dr. Tracy Nelson who patiently taught me how to think and write like a graduate student, in addition to his sharing his expertise in all things friction stir welding. Thirdly, thanks to Dr. Carl Sorensen for helping sort out the details of my analysis.

Financial support for this work was provided by the Center for Friction Stir Processing. 


\section{TABLE OF CONTENTS}

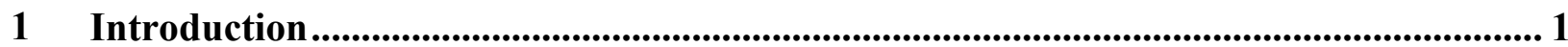

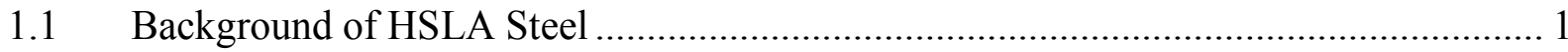

1.2 Background of Arc Welded HSLA Steel and Fracture Toughness ................................ 2

$1.3 \quad$ Background of FSW and Fracture Toughness ............................................................ 3

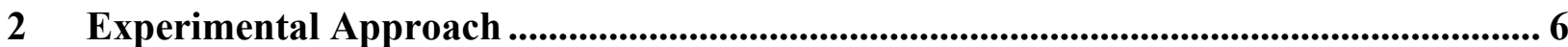

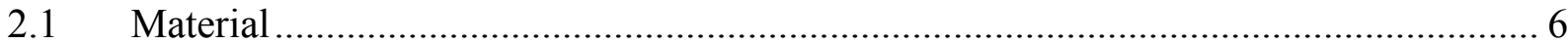

$2.2 \quad$ Welding

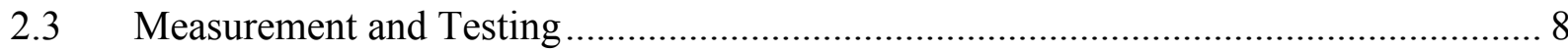

$3 \quad$ Results and Discussion............................................................................................................... 10

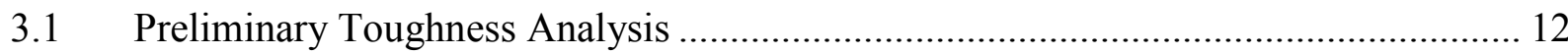

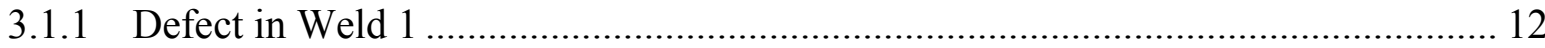

3.1.2 Variation in FSW Fracture Toughness ................................................................ 13

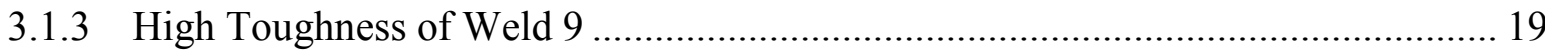

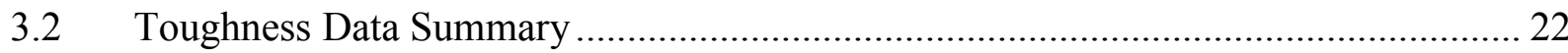

3.3 Toughness Relationships with Microstructure …………………………………...... 22

3.4 Toughness Relationships with Input Parameters ...................................................... 24

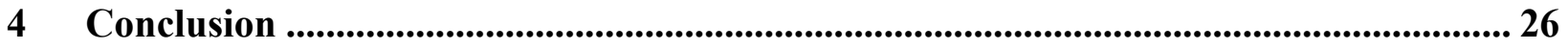

REFERENCES

Appendix A. CS4 Tool Drawing .......................................................................................... 32

Appendix B. Compact Tension Sample Drawing ….................................................................. 34

Appendix C. ASTM E1820 Thickness Independent Fracture Toughness Criteria............. 36 
Appendix D. Explored Microstructural Relationships 


\section{LIST OF TABLES}

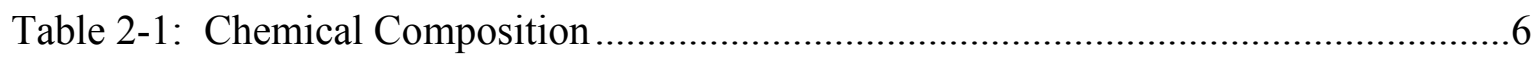

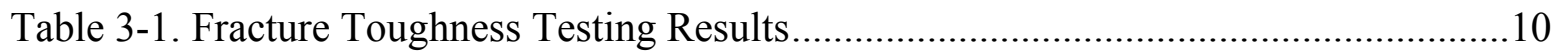

Table 3-2. Lath and Packet Measurements .........................................................................23

Table C-1. ASTM E1820 Thickness Independent Fracture Toughness Criteria ....................38 


\section{LIST OF FIGURES}

Figure 2-1: Experimental Design Space ...............................................................

Figure 2-2. Compact Tension Sample Alignment ....................................................9

Figure 3-1. BM and Weld CTOD with Industry Required Toughness Minimums ..............11

Figure 3-2. Macrograph of the Fracture Surface of Sample A [1151 J/mm, 550 RPM] .......13

Figure 3-3. CTOD as a Function of Notch Position Relative to the Centerline of Weld 5A 14

Figure 3-4. Microhardness Maps of Weld 5A [2000 J/mm, 550 RPM]. Map (A) is 800 mm Down the Length of the Weld from Map (B).............................................16

Figure 3-5. TTHF Above $245 \mathrm{HV}$ as a Function of the Distance from the Centerline of

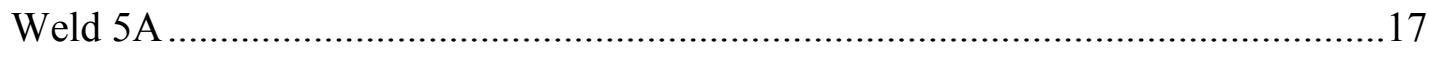

Figure 3-6. Minimum CTOD Compared to Maximum Through Thickness Hardness Fraction Above $245 \mathrm{HV}$ within $750 \mu \mathrm{m}$ of the weld centerline .............................18

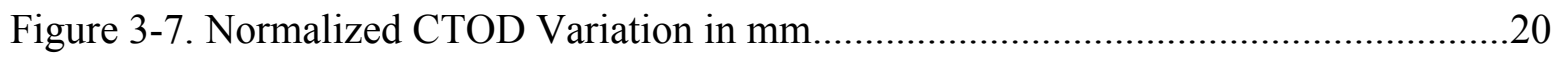

Figure 3-8. Microstructure of the Transverse Cross Section of (A) Weld 9 [2851 J/mm,

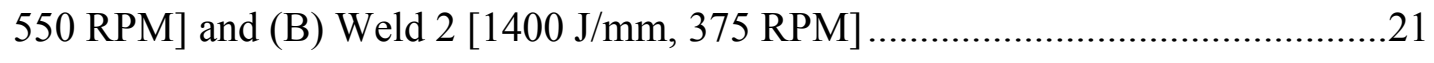

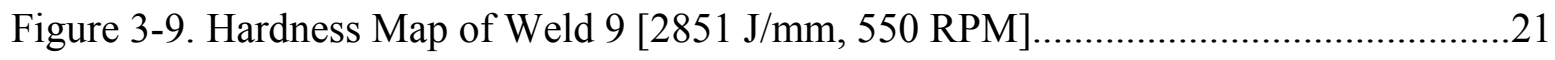

Figure 3-10. EBSD Image of (A) Weld 3 [1400 J/mm, 725 R PM] and (B) Weld 8

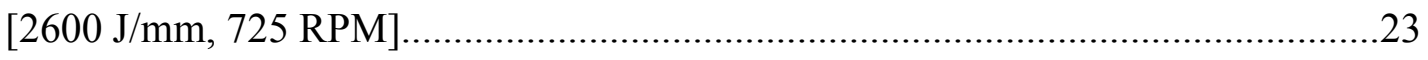

Figure 3-11. CTOD Relationship with HI and RPM ................................................25

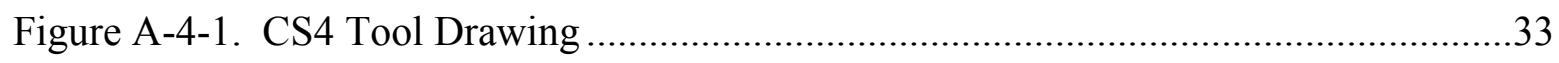

Figure B-4-2. Compact Tension Sample Dimensions ..................................................35 


\section{INTRODUCTION}

High strength low alloy (HSLA) steels have been developed to have both high yield strength and high fracture toughness. However, in practical applications steel must be welded. Traditional arc welding degrades the mechanical properties of the base metal (BM), especially in the coarse grained heat affected zone (CGHAZ) [1]. Friction stir welding (FSW) has been proposed as an alternative method of welding HSLA steels. FSW has many benefits over traditional arc welding; chief among them is that no melting is required.

Recent research on the fracture toughness of FSW HSLA steel has shown mixed results. Fairchild et al. found that FSW toughness was significantly below BM toughness [2], while Santos et al. found that weld toughness exceeded that of the BM [3]. In both studies few welding parameters were used, yielding little information on fracture toughness's relationship with FSW parameters. Because fracture toughness has been documented for only a few process operating points, it is not yet possible to make conclusions on how FSW affects toughness. This study will document and provide understanding on how FSW affects toughness over a wide range of input parameters.

\subsection{Background of HSLA Steel}

API X80, an HSLA steel designed to have high strength and high toughness specifically for pipelines [4], was used in this study. 
As in all HSLA steels grain size refinement is the primary strengthening and toughening mechanism in API X80 [5]. The fine grain size is achieved by thermomechanically controlled processing (TMCP), a combination of repeated rolling at elevated temperature followed by accelerated cooling [6]. This carefully controlled process has resulted in excellent fracture toughness in API X80, with crack tip opening displacement (CTOD) values of $0.43 \mathrm{~mm}$ being reported [3].

In addition to grain size reduction $\mathrm{TMCP}$ also results in specific microstructural constituents. Microstructures of bainite, polygonal ferrite, and martensite-austenite constituent have been observed in API X80 [3, 7]. API X80's microstructures have each contributed to its high toughness. Lower bainite has proven to increase both strength and toughness, due to its high dislocation density and refined substructure [3, 8]. Refinement in bainite packet size has also shown increased toughness and reduced ductile to brittle transition temperature [9]. Refined polygonal ferrite grains are a known ductile phase [10]. The reduction of prior austenite grain (PAG) size through TMCP has been shown to increases toughness [11-13]. Reductions in carbide sizes and distributions have also yielded improvements in toughness [12, 14-16].

\subsection{Background of Arc Welded HSLA Steel and Fracture Toughness}

HSLA steels must be welded to be used in most practical applications. However traditional arc welding causes many deleterious effects to the TMCP microstructure's size and morphology. Changes in microstructure occur when metal melts and resolidifies as a coarse grain cast microstructure. Arc welding employees a filler metal which adds alloying elements to the weld nugget. Filler can mitigate some negative effects in the weld nugget, but it cannot 
improve the heat affected zone (HAZ) because it does not melt. Therefore, the only way to control HAZ microstructure is by altering the thermal cycle of the weld.

A great deal of research has focused on understanding and improving fracture toughness of the HAZ in arc welds $[17,18]$. Many authors have reported that reducing the quantity and grain size of martensite-austenite constituent improves fracture toughness [16, 19, 20]. Shi et al. demonstrated that reducing the PAG size increased toughness [19]. Upper bainite has been established as a brittle phase[11,21], with low toughness [1,20,22], partially due to interlath carbide distribution[23].

Multiple authors have reported that heat input (HI) can be used to control the HAZ microstructure and properties [24-27]. Shimamura et al. showed that HAZ toughness increased by forming lower bainite at low HI [28]. Suarez et al. found that CTOD increased as HI decreased [29].

Despite research efforts, arc welding still results in degradation of the base metal properties.

\subsection{Background of FSW and Fracture Toughness}

FSW offers many benefits over traditional arc welding; no filler material is needed, it can be used to weld dissimilar materials, lower peak temperatures are required, and most importantly, FSW doesn't require melting. Because weld metal doesn't need to resolidify from a liquid state, the result is a fine grained wrought microstructure, which is superior to the cast microstructure of arc welding. Reported fracture toughness data in aluminum show improvements in FSW over arc welding [30]. 
FSW of HSLA steels has shown some major microstructural differences relative to arc welds. The weld nugget, or stir zone (SZ), is primarily comprised of lath ferrite that is finer than the microstructure of arc welds [31, 32]. More importantly no CGHAZ has been reported in FSW HSLA steels [7]. The SZ in FSW has also been shown to have asymmetric hardness, with a concentration of higher hardness on the advancing side of the tool. This hard zone (HZ) has been reported to contain high concentrations of lath martensite and upper bainite [7,33].

Similar to arc welding the microstructure and properties can be affected by HI. Wei as well as Ozekcin et al. indicated that the PAG, bainite lath and packet size in the SZ decreased with decreasing HI [7, 31]. Haji et al. were able to increase the hardness of the weld by lowering the HI. The change in hardness was due to increased formation of martensite at lower HI. [34]. Wade and Reynolds determined the SZ hardness asymmetry could be reduced by lowering HI in aluminum [35].

Research on the fracture toughness of FSW HSLA steel has been very limited. Over a narrow range of spindle speeds Horschel found that in HSLA 65 toughness increased with RPM. He also reported that the $\mathrm{HZ}$ was the site of lowest toughness [36]. Using only one welding parameter Fairchild et al. reported that SZ fracture toughness was significantly lower than BM in API X80 [2]. The results were so poor in fact that they did not meet their in house structural design requirements. In contrast to Horschel they also determined that the lowest toughness was not confined to the HZ, due to large PAG and high concentrations of bainite throughout the SZ.

Santos et al., using a modified X80, stated that toughness increased with a decrease in spindle speed. Over the range of spindle speeds tested toughness ranged from unacceptable to exceeding that of base metal [3]. They also found no appreciable difference between SZ and HAZ toughness. 
Previous work on the fracture toughness of FSW HSLA steels has yield mixed results. Only a limited range of parameters have been examined and the effects of HI have completely been ignored. In addition, based on the parameters reported from the studies documented, all welds have likely had medium to very high HI. High levels of HI have been shown to produce unfavorable fracture toughness. Therefore, the full extent of how fracture toughness changes as a function of FSW parameters, especially at low HI, is not yet fully understood.

This study was undertaken to fully understand how the FSW inputs of spindle speed and HI affect the fracture toughness in API X80 steel. 


\section{EXPERIMENTAL APPROACH}

\section{$2.1 \quad$ Material}

12.7 mm thick API X80 plate was used in this study. The chemical composition is found in Table 2-1. The plate was surface ground on both sides to remove any surface contamination and prepare it for welding.

Table 2-1: Chemical Composition

\begin{tabular}{|c|c|c|c|c|c|c|c|c|c|c|c|c|c|c|}
\hline Element & $\mathbf{C}$ & $\mathbf{M n}$ & $\mathbf{P}$ & $\mathbf{S}$ & $\mathbf{S i}$ & $\mathbf{N i}$ & $\mathbf{C r}$ & $\mathbf{M o}$ & $\mathbf{C u}$ & $\mathbf{A l}$ & $\mathbf{V}$ & $\mathbf{N b}$ & $\mathbf{T i}$ & $\mathbf{N}$ \\
\hline Wt. $\%$ & 0.04 & 1.7 & 0.013 & 0.001 & 0.135 & 0.147 & 0.41 & 0.005 & 0.263 & 0.031 & 0.002 & 0.102 & 0.014 & 0.006 \\
\hline
\end{tabular}

\subsection{Welding}

Welding was performed on a TTI FSW machine model RM2-3.2 using a polycrystalline cubic boron nitride E44111 CS4 tool (drawings in Appendix A). To simplify the welding process, bead-on-plate welds were used. Because of plate thickness, double sided welds were required for full penetration. After the first weld the plate was rotated so advancing sides of the second weld pass was aligned with the first.

The design variables chosen for this study were tool rotational speed and HI. Although, $\mathrm{HI}$ is not a machine parameter, it is calculated from of travel speed, rotational spindle speed, and the motor torque [37]. Even though HI is coupled with the spindle speed, during preliminary testing it was determined that travel speed has a significantly greater effect than spindle speed. To achieve a constant HI, travel speed was manually adjusted to keep HI within $\pm 2.5 \%$ of the 
desired value. Tool position in the vertical axis was manually adjusted to match variations in the plate thickness and anvil flatness, resulting in a constant plunge depth.

The design space was chosen so that it would cover the greatest possible range of input parameters. A preliminary study was done to determine the maximum and minimum HI and spindle speed that could be used without exceeding maximum tool loads and resulted in sound welds. Welding parameters were then chosen using a central composite design, shown in Figure 2-1. A central composite design allows for the building of a response surface to find the optimal parameters.

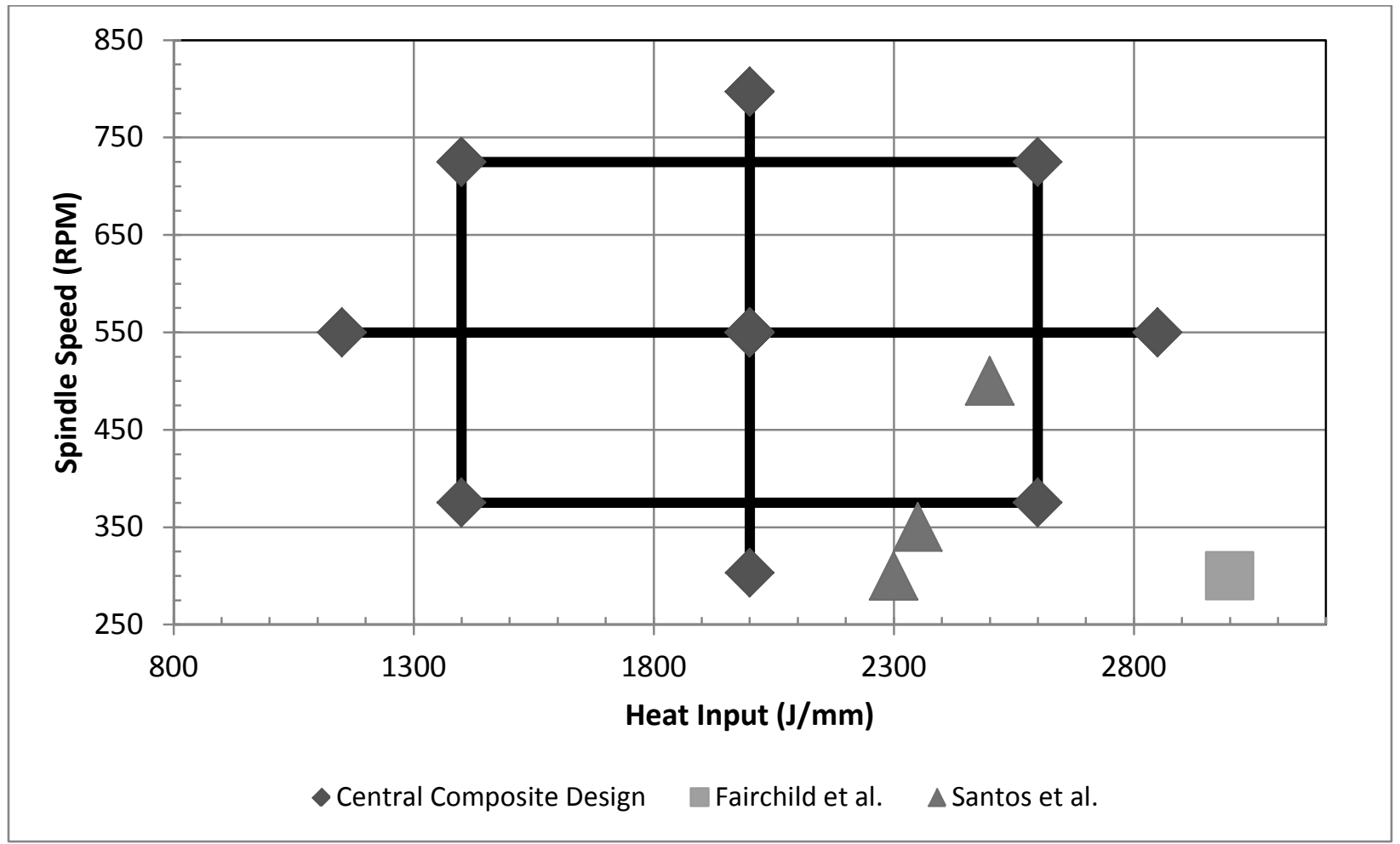

Figure 2-1: Experimental Design Space 
Figure 2-1 also shows the spindle speed and estimated HI of both Fairchild et al. [2] and Santos et al. [3]. While these numbers are estimates based on the spindle speed and travel speeds reported in each study, they illustrate the narrow range of parameters that had previously been tested.

\subsection{Measurement and Testing}

Post weld analyses were done to measure hardness and quantify microstructure. Samples were polished and hardness was measured at points spaced $0.5 \times 0.5 \mathrm{~mm}$ apart. Hardness measurement points were then used to create microhardness maps for the entire cross section. Microhardness maps were then used to identify the HZ and center of the SZ for later microstructural analysis. EBSD scans were performed at two locations. Location $1 \mathrm{w}$ as the nugget center, which in this study was defined as $2750 \mu \mathrm{ms}$ from the surface at the center of weld pass two. Location 2 was the area between the peak hardness points on the centerline of the hardness map. EBSD scans were $250 \times 250 \mu \mathrm{m}$ at a step size of $0.12 \mu \mathrm{m}$.

Fracture toughness testing was performed using stepped notch compact tension (CT) samples according to ASTM E1820 [38]. Sample width was $50.8 \mathrm{~mm}$, and thickness after welding and machining was $10.3 \mathrm{~m} \mathrm{~m}$. CT sample engineering drawings can be found in Appendix B. Samples were oriented such that the weld centerline was sampled, as shown in Figure 2-2. All testing was performed at room temperature. 


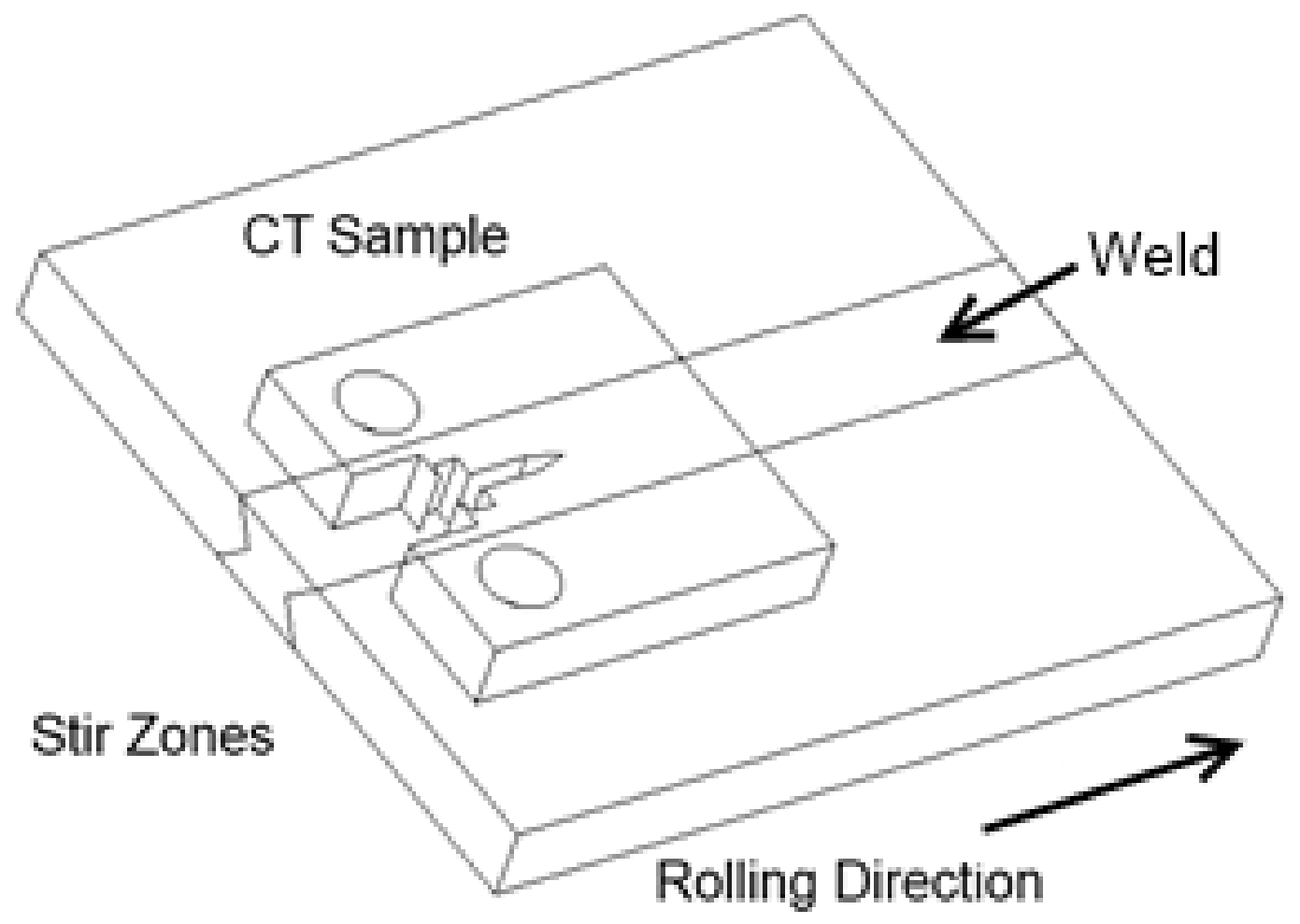

Figure 2-2. Compact Tension Sample Alignment 


\section{RESULTS AND DISCUSSION}

The result of all fracture toughness testing is shown in Table 3-1 in order of descending

HI. Table 3-1 also shows final propagation state, and geometry dependent $\mathrm{J}_{\mathrm{Q}}$ and $\mathrm{CTOD}_{\mathrm{Q}}$.

Table 3-1. Fracture Toughness Testing Results

\begin{tabular}{|c|c|c|c|c|c|c|c|}
\hline Sample & $\begin{array}{c}\text { Weld } \\
\# \\
\end{array}$ & $\begin{array}{c}\text { Heat Input } \\
(\mathrm{J} / \mathrm{mm})\end{array}$ & $\begin{array}{c}\text { Spindle } \\
\text { Speed (RPM) } \\
\end{array}$ & $\begin{array}{c}\text { Travel Speed } \\
(\mathrm{mm} / \mathrm{min})\end{array}$ & $\begin{array}{c}\text { Final } \\
\text { Propagation }\end{array}$ & $\begin{array}{c}\mathbf{J}_{\mathbf{Q}} \\
(\mathbf{N} / \mathbf{m m})\end{array}$ & $\begin{array}{c}\text { CTOD }_{Q} \\
(\mathrm{~mm})\end{array}$ \\
\hline$A^{*}$ & 1 & 1151 & 550 & 287 & Stable & 471 & 0.318 \\
\hline $\mathrm{B}^{*}$ & 1 & 1151 & 550 & 287 & Stable & 628 & 0.427 \\
\hline $\mathrm{C}$ & 2 & 1400 & 375 & 194 & Stable & 694 & 0.45 \\
\hline $\mathrm{D}$ & 3 & 1400 & 725 & 235 & Stable & 470 & 0.322 \\
\hline $\mathrm{E}$ & 3 & 1400 & 725 & 235 & Stable & 849 & 0.596 \\
\hline $\mathrm{F}$ & 3 & 1400 & 725 & 235 & Stable & 464 & 0.294 \\
\hline $\mathrm{G}$ & 4 & 2000 & 303 & 126 & Stable & 520 & 0.36 \\
\hline $\mathrm{H}$ & $5 \mathrm{~A}$ & 2000 & 550 & 121 & Stable & 449 & 0.32 \\
\hline $\mathrm{I}$ & $5 \mathrm{~A}$ & 2000 & 550 & 121 & Stable & 504 & 0.355 \\
\hline $\mathrm{J}$ & $5 \mathbf{A}$ & 2000 & 550 & 121 & Stable & 445 & 0.329 \\
\hline $\mathrm{K}$ & $5 \mathbf{A}$ & 2000 & 550 & 121 & Stable & 945 & 0.751 \\
\hline $\mathrm{L}$ & $5 \mathrm{~A}$ & 2000 & 550 & 121 & Instable & 794 & 0.64 \\
\hline $\mathrm{M}$ & $5 \mathrm{~A}$ & 2000 & 550 & 121 & Stable & 410 & 0.293 \\
\hline $\mathrm{N}$ & $5 \mathbf{A}$ & 2000 & 550 & 121 & Stable & 503 & 0.349 \\
\hline $\mathrm{O}$ & $5 \mathbf{A}$ & 2000 & 550 & 121 & Stable & 648 & 0.461 \\
\hline $\mathrm{P}$ & 5B & 2000 & 550 & 121 & Stable & 724 & 0.497 \\
\hline Q & $5 B$ & 2000 & 550 & 121 & Crack Blunted & NA & $\mathrm{NA}$ \\
\hline $\mathrm{R}$ & $5 \mathrm{C}$ & 2000 & 550 & 121 & Stable & 618 & 0.428 \\
\hline $\mathrm{S}$ & $5 \mathrm{C}$ & 2000 & 550 & 121 & Stable & 829 & 0.519 \\
\hline $\mathrm{T}$ & 6 & 2000 & 797 & 152 & Instable & 665 & 0.357 \\
\hline $\mathrm{U}$ & 6 & 2000 & 797 & 152 & Instable & 441 & 0.305 \\
\hline $\mathrm{V}$ & 6 & 2000 & 797 & 152 & Stable & 1059 & 0.661 \\
\hline $\mathrm{W}$ & 7 & 2600 & 375 & 98 & Stable & 490 & 0.311 \\
\hline $\mathrm{X}$ & 8 & 2600 & 725 & 93 & Instable & 261 & 0.243 \\
\hline $\mathrm{Y}$ & 9 & 2849 & 550 & 82 & Stable & 987 & 0.639 \\
\hline
\end{tabular}


Table 3-1. Continued

\begin{tabular}{|c|c|c|c|c|c|c|c|}
\hline Sample & $\begin{array}{c}\text { Weld } \\
\#\end{array}$ & $\begin{array}{c}\text { Heat Input } \\
(\mathbf{J} / \mathbf{m m})\end{array}$ & $\begin{array}{c}\text { Spindle } \\
\text { Speed (RPM) }\end{array}$ & $\begin{array}{c}\text { Travel Speed } \\
(\mathbf{m m} / \mathbf{m i n})\end{array}$ & $\begin{array}{c}\text { Final } \\
\text { Propagation }\end{array}$ & $\begin{array}{c}\mathbf{J}_{\mathbf{Q}} \\
\mathbf{( N / m m )}\end{array}$ & $\begin{array}{c}\mathbf{C T O D}_{\mathbf{Q}} \\
(\mathbf{m m})\end{array}$ \\
\hline Z & $\mathbf{9}$ & 2849 & 550 & 82 & Instable & 902 & 0.607 \\
\hline AA & BM & Base Metal & Base Metal & Base Metal & Stable & 598 & 0.472 \\
\hline AB & BM & Base Metal & Base Metal & Base Metal & Stable & 641 & 0.465 \\
\hline AC & BM & Base Metal & Base Metal & Base Metal & Stable & 629 & 0.494 \\
\hline AD & BM & Base Metal & Base Metal & Base Metal & Stable & 624 & 0.511 \\
\hline AE & BM & Base Metal & Base Metal & Base Metal & Stable & 662 & 0.472 \\
\hline
\end{tabular}

*Weld Defect

Figure 3-1 shows CTOD values for both BM and welds. Weld CTOD values range from 0.243 to $0.751 \mathrm{~m} \mathrm{~m}$. The base metal averaged $0.483 \mathrm{~mm}$. At room temperature all welding parameters yielded CTOD values that exceeded API Standard $1104(0.10 \mathrm{~mm})$ and DNV-OSF101 $(0.15 \mathrm{~mm})$ minimum CTOD requirements. In most cases CTOD was more than double the requirements outlined in the specifications.

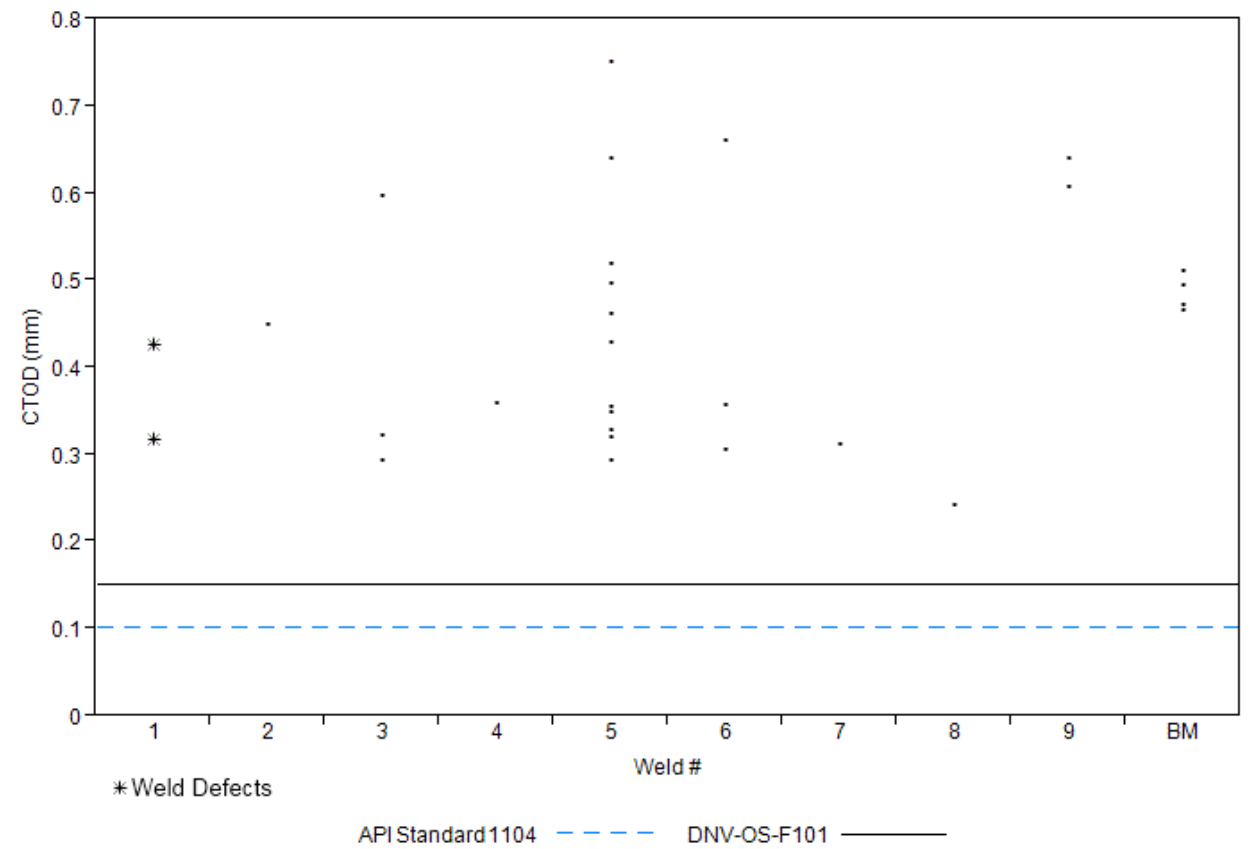

Figure 3-1. BM and Weld CTOD with Industry Required Toughness Minimums 
Despite the excellent toughness, the BM and welded samples failed to meet all ASTM E1820 criteria. There are 12 criteria that must be met in order to calculate geometry independent toughness. The criteria that were not met dealt primarily with the requirements to have uniform crack growth and a uniform crack front. Uniformity of the crack is important because the compliance of the CT sample is used to estimate crack length. If a crack has a nonuniform crack front, compliance will produce less accurate crack length estimations. A complete breakdown of the criteria met for each sample can be found in Appendix C.

In the absence of geometry independent toughness, geometry dependent toughness can be used to compare similar samples. In this study samples were held to a constant thickness; therefore comparisons among the samples used are valid.

\subsection{Preliminary Toughness Analysis}

From the data in Figure 3-1 there are three things that must first be discussed before relationships with FSW parameters can be established. First, both samples in weld 1 fractured along a weld defect. Second, the variation of CTOD values within a given weld was significantly larger than the variation in the BM. Lastly, both samples in weld 9 ha d substantially higher minimum toughness than other welds and BM despite having the highest HI. These will be discussed below.

\subsubsection{Defect in Weld 1}

There was a visible defect on the fracture surface of both samples from weld 1 [1151 $\mathrm{J} / \mathrm{mm}, 550 \mathrm{R}$ PM]. Figure 3-2 shows a $\mathrm{m}$ acrograph of the fracture surface of sample A. The defect is at the root of the pin in the advancing side of the first weld pass. The serrations on the 
defect are $0.5 \mathrm{~mm}$ apart. The distance between serrations is the same as the distance the tool travels to complete one full revolution. The defect was likely caused by the low HI coupled with insufficient forging force.

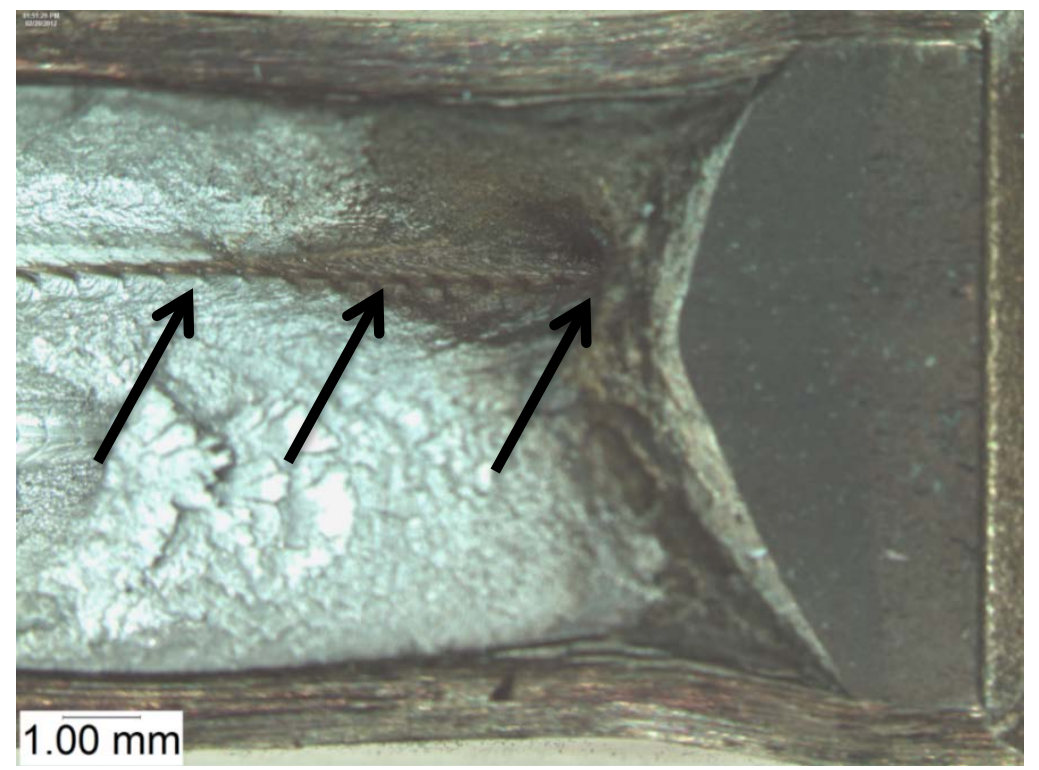

Figure 3-2. Macrograph of the Fracture Surface of Sample A [1151 J/mm, 550 RPM]

Despite the defect the toughness of both samples in weld 1 are 1) above the minimum requirements and 2) not the lowest of the welds tested. Because these samples have defects they do not accurately represent SZ toughness and will not be included in later analysis.

\subsubsection{Variation in FSW Fracture Toughness}

The second concern is the large variations in sample toughness of welds 3,5 , and 6 (shown in Figure 3-1). The standard deviation in samples from welds 3, 5, and 6 were 0.157 $\mathrm{mm}$, whereas the BM standard deviation was only $0.019 \mathrm{~mm}$. The welded sample variation is 
8.3 times greater than BM variation. Standard deviations of this magnitude make it difficult to analyze the data because they cause there to be no statistical difference between any of the welds.

Previous research in HSLA FSW toughness also showed high levels of CTOD variation $[2,3]$. None of the previous work has made any attempt to explain it. In this work, many sources of variation were examined. These sources include testing and measurement methods, tool temperature, inhomogeneity along the length of the weld. In the end a single factor -weld inhomogeneity-appears to account for almost all the variation. This will be shown below.

Figure 3-3 shows CTOD as a function of the CT sample notch placement relative to the centerline for weld 5A. To determine the notch location the CT samples were etched so the SZ could be seen. Deviations from the centerline were determined by measuring the location of the side grooves on the $\mathrm{CT}$ sample in relation to the center of the stir zone.

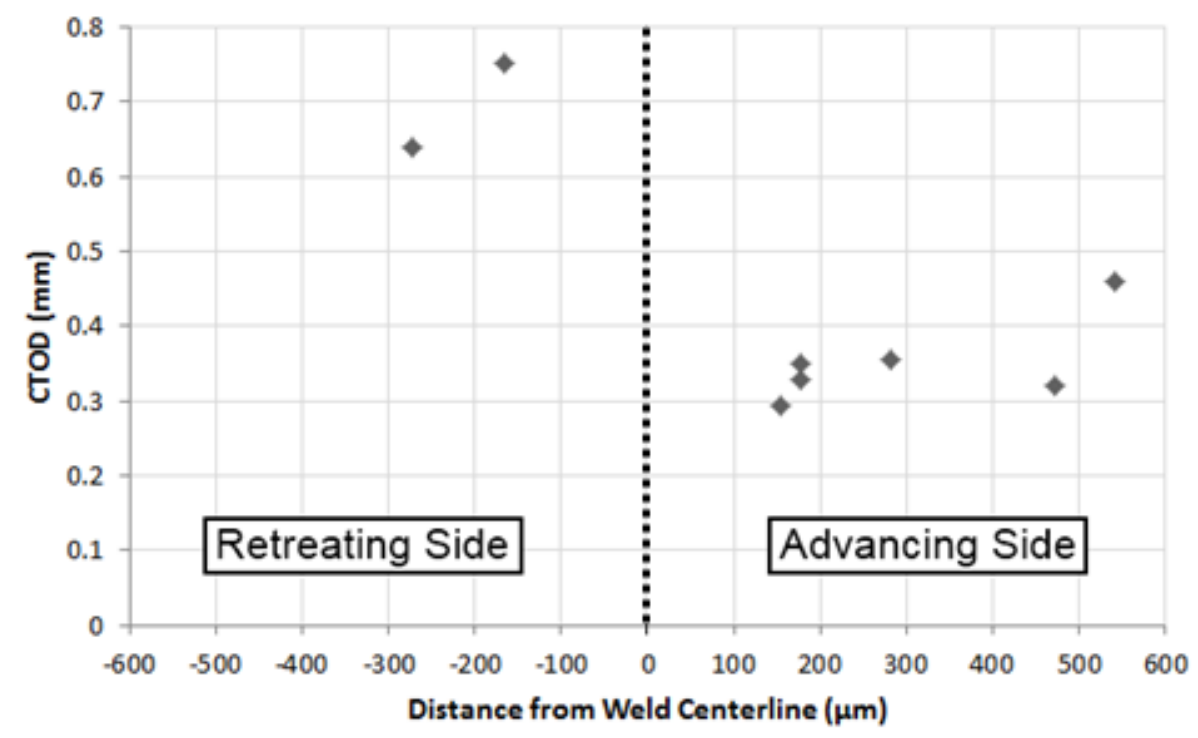

Figure 3-3. CTOD as a Function of Notch Position Relative to the Centerline of Weld 5A 
CTOD values in the advancing side are $50 \%$ of those in the retreating side. This trend is the same in all samples with multiple CTOD values, except weld 9 which will be discussed later.

There is likely some significant microstructural difference between the retreating and advancing sides to cause a $50 \%$ drop in toughness. EBSD scans could be used to gather microstructure measurements, however changes in lath and packet sizes would likely be gradual and differences would be hard to capture. Microhardness, however, is a material property that accurately captures changes in the material from location to location and from weld to weld. Therefore, microhardness will be used to measure stir zone inhomogeneity.

Figure 3-4 shows microhardness maps for 2 locations in weld 5A. Location A is $800 \mathrm{~mm}$ down the length of the weld from location B. In all microhardness maps weld pass 1 is on top and weld pass 2 is on the bottom. In Figure 3-4A and B the hardness is significantly higher in weld pass two on the advancing side. While in weld pass one the increase in hardness from retreating to advancing side is less distinct. To quantify the change in hardness from retreating to advancing side a metric of the through thickness hardness fraction (TTHF) above $245 \mathrm{HV}$ was developed.

The TTHF is defined as the percentage of points that measured above $245 \mathrm{HV}$ on a single, through thickness line of microhardness indents, like the dotted lines on both Figure 3-4A and B. $245 \mathrm{HV}$ was chosen because it is higher than BM, but low enough to allow the welds to be differentiable from each other. Due to material removal during the CT sample side grooving process, the $1000 \mu \mathrm{m}$ next to the surface of weld pass 1 and 2 were ignored while calculating TTHF. 


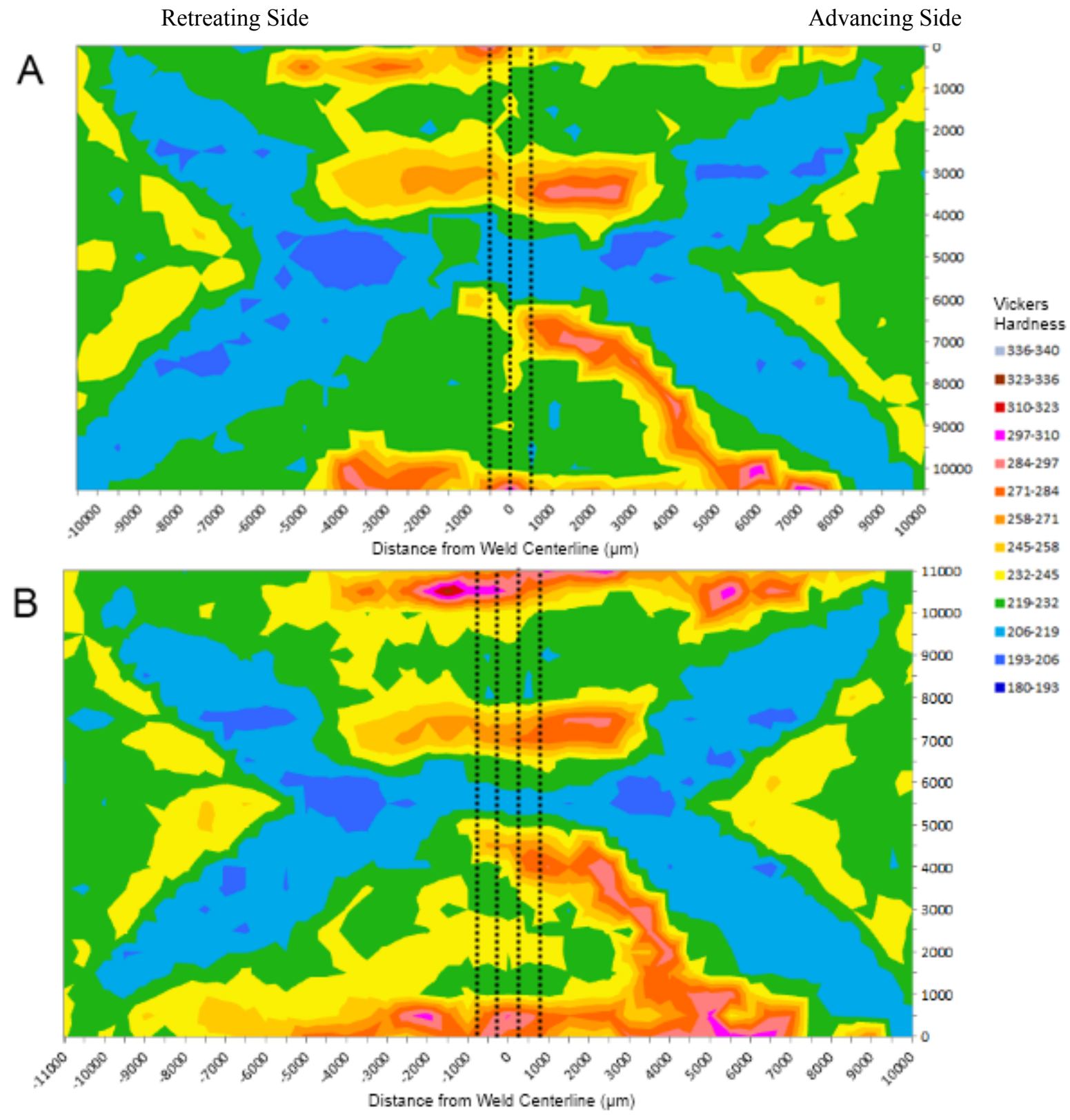

Figure 3-4. Microhardness Maps of Weld 5A [2000 J/mm, $550 \mathrm{RPM}]$. Map (A) is $800 \mathrm{~mm}$ Down the Length of the Weld from Map (B).

TTHF was calculated for each through thickness line from 750 to $-750 \mu \mathrm{m}$ as shown in Figure 3-4A and B. It should be noted that center of the stir zone did not always line up with a 
through thickness line of the microhardness indents, as shown in Figure 3-4B. Each weld had multiple microhardness maps from which TTHF was calculated.

Figure 3-5 the all of the TTHF measurements for weld 5A, as well as a quadratic curve fit of the data with an $\mathrm{R}^{2}$ value of $61 \%$. The curve fit of TTHF increases from $12 \%$ on the retreating side to $26 \%$ on the advancing side. This trend of increasing TTHF from retreating to advancing side was true in all welds, except weld 9 as previously noted. Because the quadratic fit includes TTHF percentages from multiple locations along the length of the weld it is an estimate of the inhomogeneity of the entire weld.

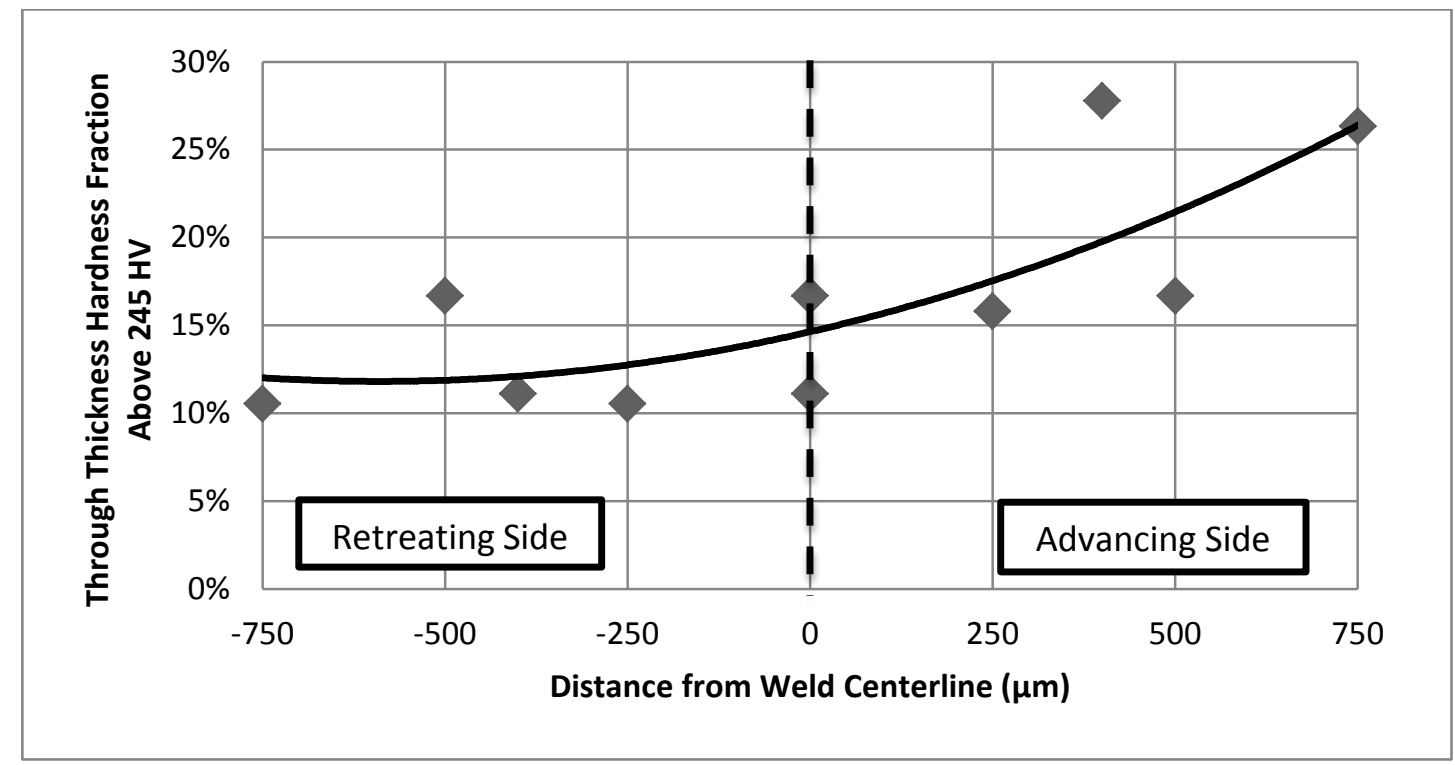

Figure 3-5. TTHF Above $245 \mathrm{HV}$ as a Function of the Distance from the Centerline of Weld 5A

When the data in Figure 3-3 and Figure 3-5 are examined together it can be seen that CTOD increases with decreasing TTHF. From this trend a relationship of minimum toughness to maximum TTHF can be established, this relationship will be expanded in the following paragraphs. 
These results suggest that as the notch position varies the crack samples a highly inhomogeneous microstructure in the SZ, which leads to variation in fracture toughness. The decreasing fracture toughness and increasing TTHF indicates that the HZ will have the lowest toughness in the weld. These results are in agreement with Horschel [36] but contradictory to the findings reported by Fairchild et al. [2]. However, the contradiction with Fairchild et al. is not surprising due to the large grains and elevated hardness that was reported throughout their stir zone.

Figure 3-6 shows minimum CTOD as a function of maximum TTHF within $750 \mu \mathrm{m}$ of the weld centerline for each weld, BM is also included. Without weld 9 (solid line), Figure 3-6 shows a prototypical trend in which CTOD increased by $92 \%$ as the centerline TTHF decreased linearly by $89 \%$. Weld 9 is an obvious outlier, with both high toughness and high TTHF. Weld 9 will be discussed further in the next section.

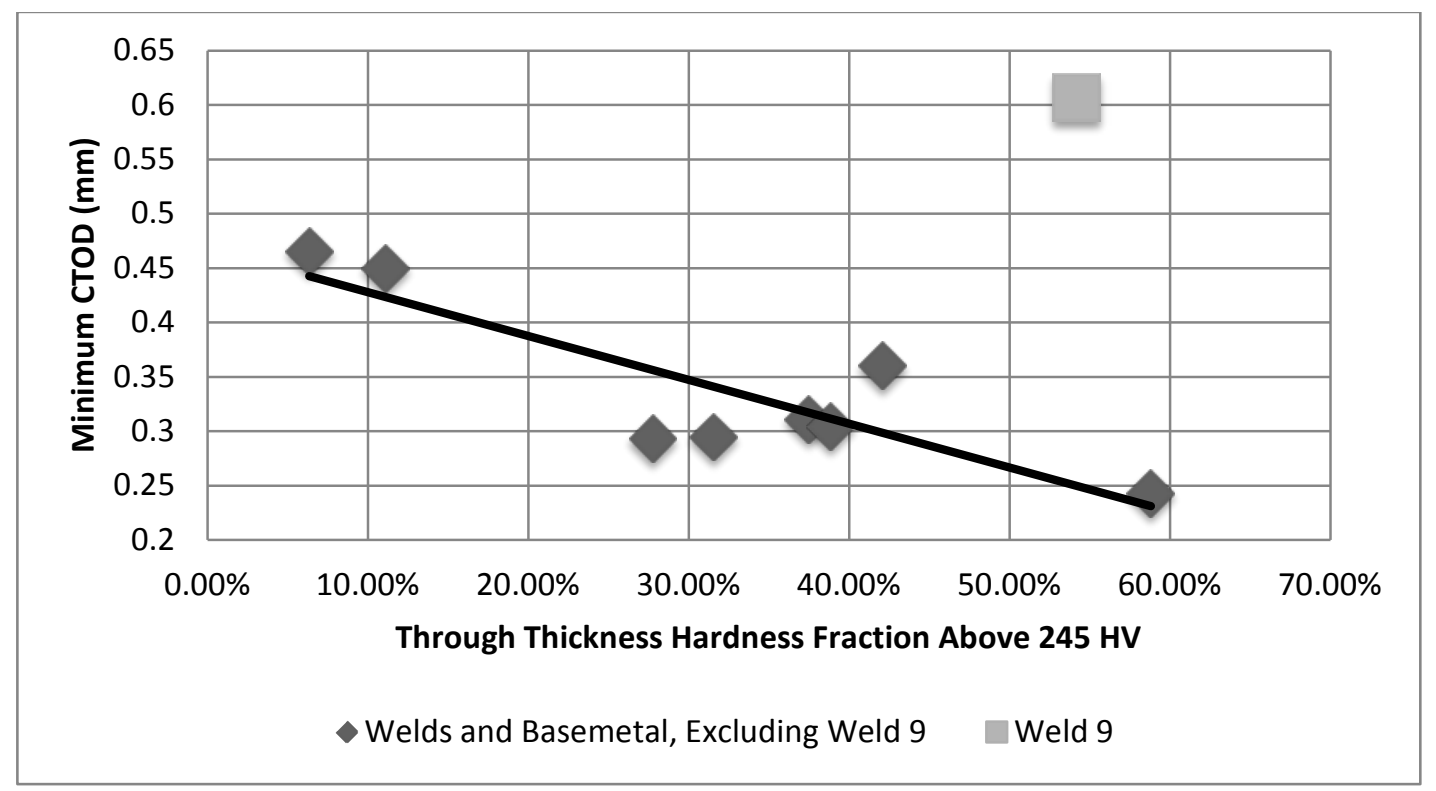

Figure 3-6. Minimum CTOD Compared to Maximum Through Thickness Hardness Fraction Above 245 HV within $750 \mu \mathrm{m}$ of the weld centerline 
Figure 3-6 illustrates that toughness in FSW can be improved by reducing TTHF. Reductions in TTHF result in a more homogeneous microstructure, by having fewer points of high hardness. Weld 2 [375 RPM, $1400 \mathrm{~J} / \mathrm{mm}$ ] is a prime example of low TTHF and high minimum toughness, with only an $11 \%$ maximum TTHF within $750 \mu \mathrm{m}$ of the weld centerline and a minimum toughness of $0.450 \mathrm{~mm}$.

Regardless of the cause of variation, large standard deviations make data analysis problematic. High variation makes it difficult to establish correlations between CTOD values, welding inputs, and microstructure measurements. High variations also make a single representative toughness value uncertain.

To understand the distribution of toughness variation the data was normalized by subtracting each CTOD value from the minimum value of its respective weld. Only welds that had multiple CTOD values were used in these calculations.

Figure 3-7 shows the normalized CTOD values. It is clear that the normalized data is largely concentrated around the minimum. A minimum CTOD value is also a safe and conservative estimation of toughness. Therefore, the minimum CTOD value will be used in all subsequent analysis.

\subsubsection{High Toughness of Weld 9}

The last concern with the data in Figure 3-1 is that the CTOD values for both samples in weld $9[2851 \mathrm{~J} / \mathrm{mm}, 550 \mathrm{RPM}]$ are significantly higher than other welds as well as the BM. Because of the high HI in weld 9 it was expected that large grains would form resulting in reduce fracture toughness. However, weld 9 had a minimum sample CTOD of $0.607 \mathrm{~mm}$, which 
was $34 \%$ higher than the closest weld and $30 \%$ higher than BM. To determine the cause of the high CTOD value weld 9 was examined further.

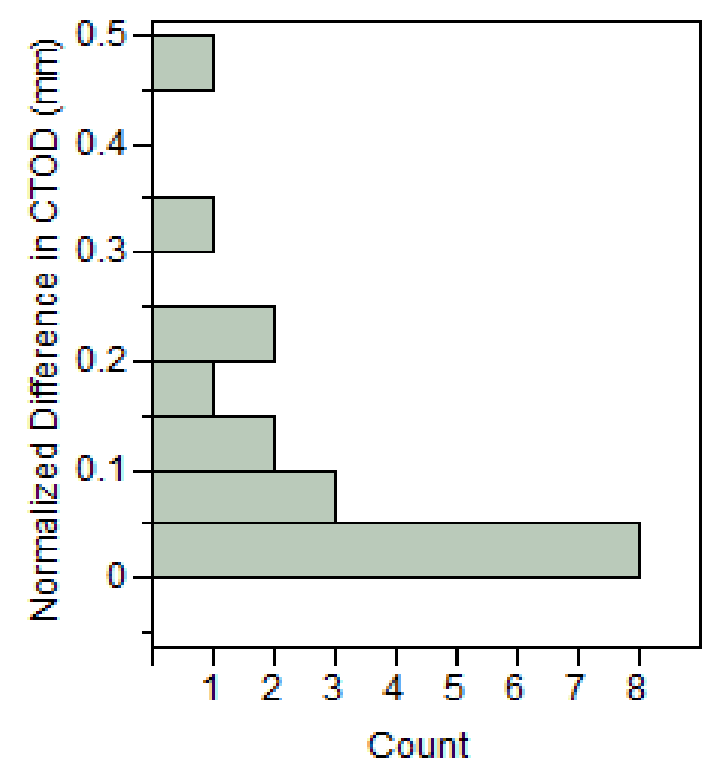

Figure 3-7. Normalized CTOD Variation in $\mathbf{m m}$

In Figure 3-6 weld 9 was alone in having both a high CTOD and high TTHF. This was surprising and merited more investigation.

Figure 3-8 shows the microstructure of the transverse cross section of (A) weld 9 [2851 $\mathrm{J} / \mathrm{mm}, 550 \mathrm{RPM}]$, and (B) weld 2 [1400 J/mm, $375 \mathrm{RPM}]$. Traditionally in steel FSW a small hard $\mathrm{HZ}$ is present in the advancing side of the weld, as shown on $\mathrm{r}$ ight side Figure 3-8B. However in Figure 3-8A, the HZ formed in large bands that swept from the advancing side (right) to the retreating side (left) of weld 9. 


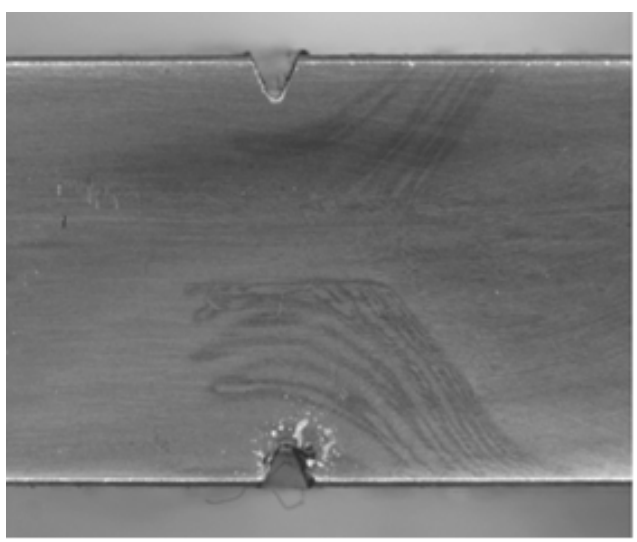

A)

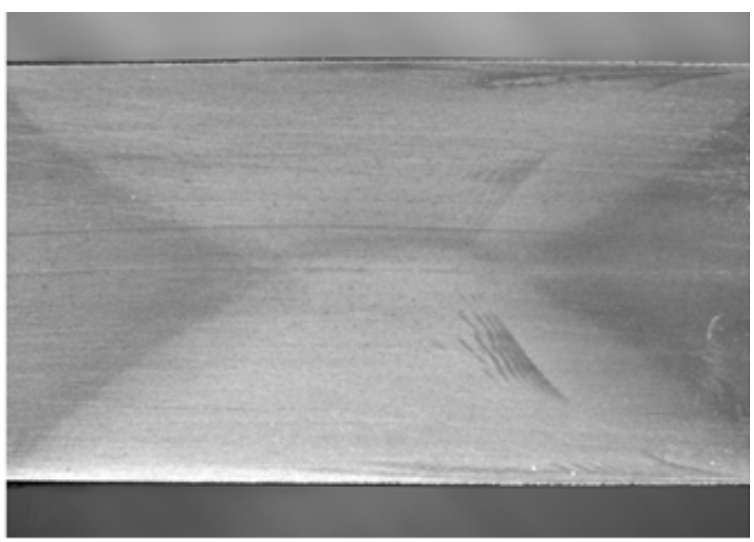

B)

Figure 3-8. Microstructure of the Transverse Cross Section of (A) Weld 9 [2851 J/mm, 550 RPM] and (B) Weld 2 [1400 J/mm, 375 RPM]

Figure 3-9 shows a microhardness map of weld 9. The bands visible in Figure 3-8A can be seen as bands of high and low hardness alternating across the SZs in Figure 3-9. The peak hardness in these bands was over $300 \mathrm{HV}$ and the minimums between bands were as soft as $\mathrm{BM}$, under $230 \mathrm{HV}$. The bands had an average spacing of $1350 \mu \mathrm{m}$ from peak to peak. These bands are more defined in weld pass two (bottom) with higher peaks and lower valleys relative to weld pass one (top). This is likely due to weld pass two tempering weld pass one.

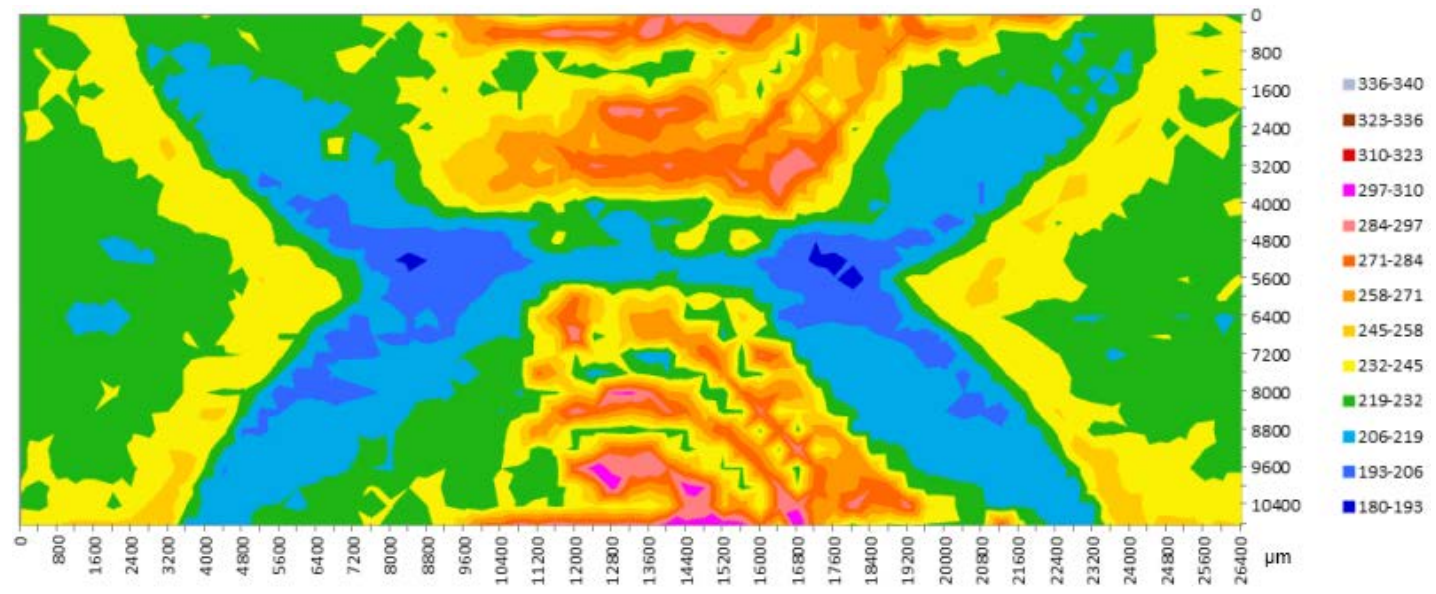

Figure 3-9. Hardness Map of Weld 9 [2851 J/mm, 550 RPM] 
The high toughness in weld 9 is likely the result of its unique microstructure. The high CTOD value is attributed to the HZ's banded structure across the centerline. Bands in the HZ create a "crack divider" configuration which has been shown to increase toughness [5]. These bands may be a result of the high HI SZ asymmetry described by Wade and Reynolds [35]. The repeatability of the $\mathrm{HZ}$ bands in all high $\mathrm{HI}$ welds is unclear; therefore weld 9 will be removed from the remainder of the analysis.

\subsection{Toughness Data Summary}

Based on the analysis presented above the minimum CTOD value for each weld will be used as the representative value for subsequent analysis. Because of the defect in weld 1 and the unique hard zone in weld 9 both welds have been removed from the data set.

Relationships will be made below using this reduced data set in an attempt to understand how microstructure and the process inputs of HI and spindle speed affect fracture toughness. These relationships will then be used to determine how to produce welds with the highest toughness.

\subsection{Toughness Relationships with Microstructure}

EBSD images for weld 3 [1400 J/mm, 725 RPM] and weld 8 [2600 J/mm, 725 RPM] are shown in Figure 3-10A and B, respectively. All welds had a predominantly lath ferrite microstructure, with small islands of polygonal ferrite at lower HI. 


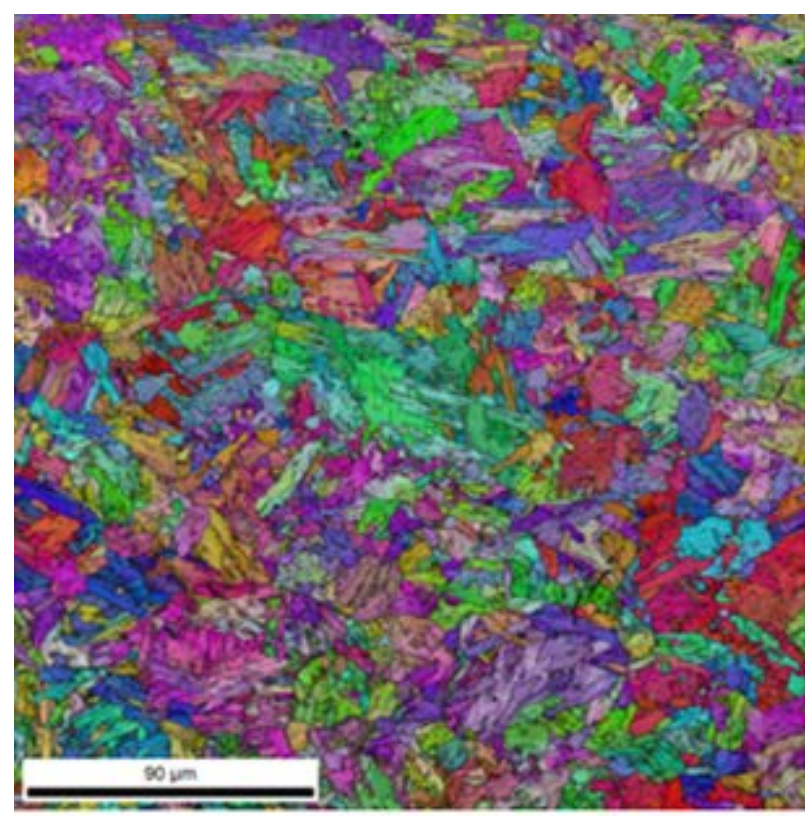

A)

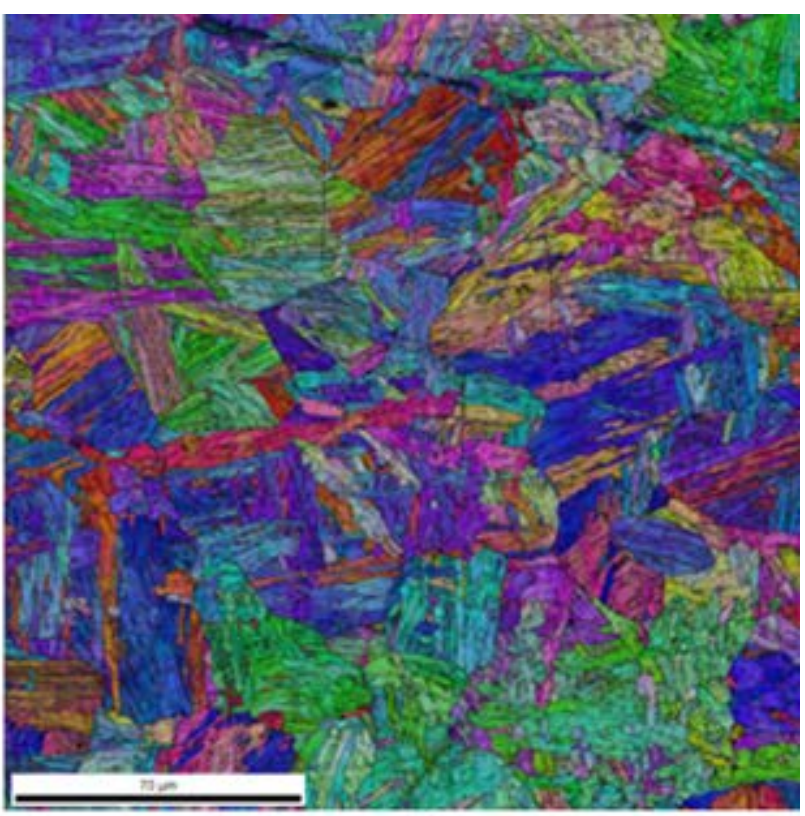

B)

Figure 3-10. EBSD Image of (A) Weld 3 [1400 J/mm, 725 RPM] and (B) Weld 8 [2600 J/mm, 725 RPM]

Lath and packet measurements from the SZ of each weld are shown in Table 3-2. Lath measurements ranged from 0.806 to $2.09 \mu \mathrm{m}$ and packet measurements ranged from 3.05 to $9.79 \mu \mathrm{m}$.

Table 3-2. Lath and Packet Measurements

\begin{tabular}{|c|c|c|c|c|c|c|}
\cline { 3 - 7 } \multicolumn{2}{c|}{} & \multicolumn{2}{c|}{ Nugget Center } & \multicolumn{2}{c|}{ Centerline Hardest Area } \\
\hline Weld Number & $\begin{array}{c}\text { Heat Input } \\
(\mathbf{J} / \mathbf{m m})\end{array}$ & $\mathbf{R P M}$ & $\begin{array}{c}\text { Lath Width } \\
(\boldsymbol{\mu m})\end{array}$ & $\begin{array}{c}\text { Packet Size } \\
(\boldsymbol{\mu m})\end{array}$ & $\begin{array}{c}\text { Lath Width } \\
(\boldsymbol{\mu m})\end{array}$ & $\begin{array}{c}\text { Packet Size } \\
(\boldsymbol{\mu m})\end{array}$ \\
\hline 2 & 1400 & 375 & 1.12 & 5.405 & 1.312 & 6.258 \\
\hline 3 & 1400 & 725 & 1.395 & 7.654 & 1.7 & 5.445 \\
\hline 4 & 2000 & 303 & 1.856 & 5.364 & 1.665 & 6.561 \\
\hline $5 \mathrm{~A}$ & 2000 & 550 & 1.334 & 7.398 & 1.261 & 9.03 \\
\hline 6 & 2000 & 797 & 1.599 & 7.113 & 1.593 & 5.159 \\
\hline 7 & 2600 & 375 & 2.091 & 7.72 & 1.393 & 6.372 \\
\hline 8 & 2600 & 725 & 0.913 & 7.286 & 0.806 & 3.63 \\
\hline 9 & 2849 & 550 & 1.847 & 9.791 & 0.969 & 3.055 \\
\hline
\end{tabular}


While previous work reported linear relationships between HI and both lath and packet size, no relationships were found in this study (see Appendix D for more details on the possible relationships that were examined). This was likely due to the following reasons.

In Figure 3-5 that CTOD and TTHF over 245 HV change greatly over just a few hundred microns. Therefore, because of the comparatively large area, the EBSD scans likely sampled a changing microstructure from retreating to advancing side of the weld.

It is likely there were no microstructural relationships at the hardest area on the centerline because the peak hardness is not the key factor in SZ fracture toughness, but rather the effects of inhomogeneous microstructure near the centerline, as shown by the changing TTHF in Figure $3-5$.

\subsection{Toughness Relationships with Input Parameters}

Figure 3-11 shows the minimum CTOD as a function of both HI and spindle speed. Fracture toughness increased linearly from 0.243 to $0.450 \mathrm{~mm}(85 \%)$, with a corresponding decrease in $\mathrm{HI}$ from 2600 to $1400 \mathrm{~J} / \mathrm{mm}(46 \%)$. The same increase in toughness was also a result of a decrease in spindle speed from 800 to 300 R PM (53\%). Highest toughness results from low spindle speed and low HI.

CTOD relationships with both $\mathrm{HI}$ and spindle speed have been individually established by previous work $[3,28,29,36]$. Spindle speed has been determined to be a factor in CTOD in FSW $[3,36]$. This work establishes that by decreasing both HI and spindle speed the SZ fracture toughness of FSW HSLA steel can be increased. In addition, the magnitude of spindle speed and HI are almost identical. 


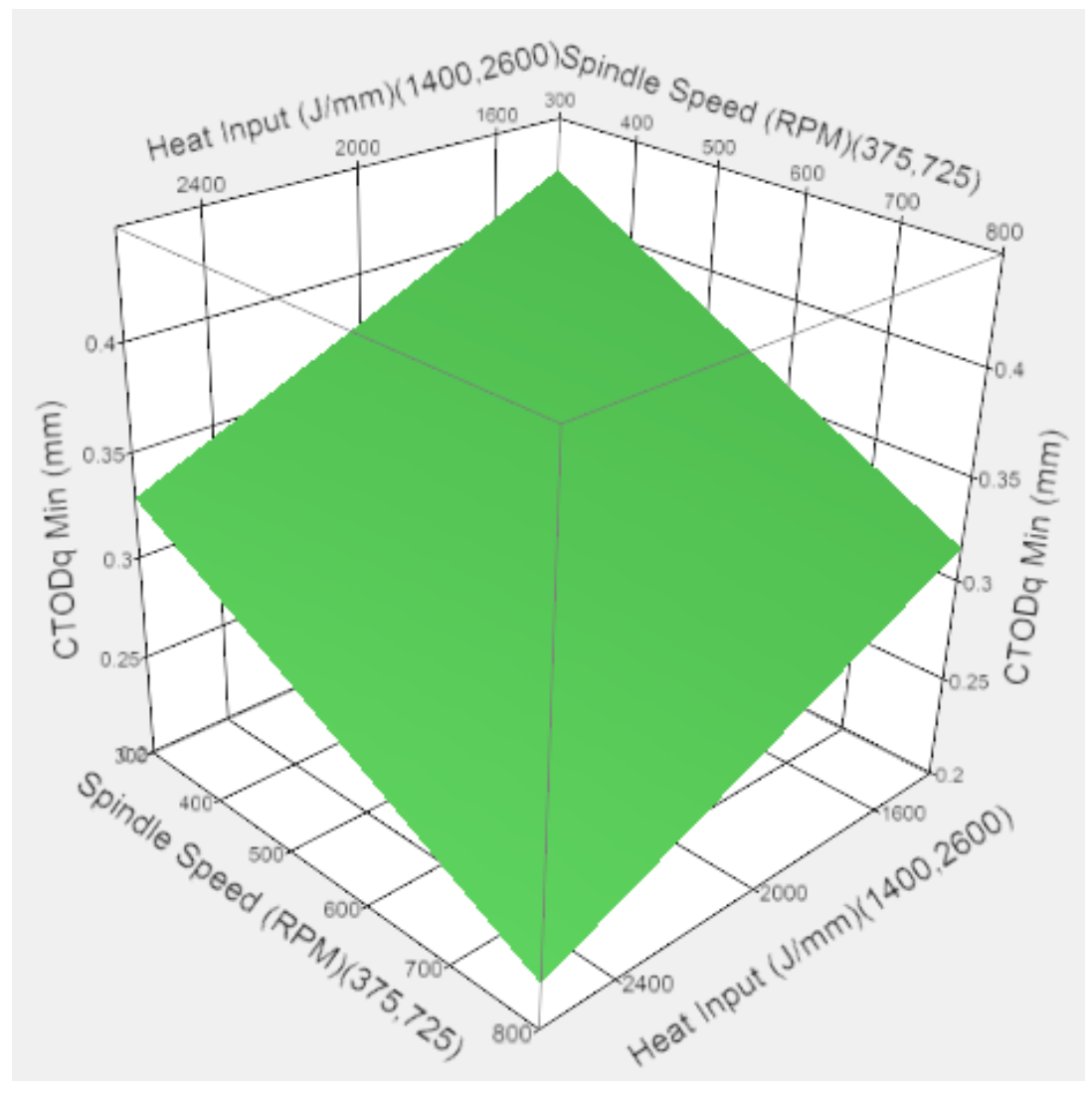

Figure 3-11. CTOD Relationship with HI and RPM

Work by Fairchild et al. stated that FSW HSLA did not meet the design requirements for pipeline applications [2]. In that work however, a slow travel speed, which would create high HI, was used. This work has shown that high HI will be detrimental to fracture toughness. By using a low HI and low spindle speed weld this work has produced a weld with a minimum CTOD only 7\% below BM [Weld 2, $1400 \mathrm{~J} / \mathrm{mm}, 375 \mathrm{RPM}$ ], which would likely meet pipeline design requirements. 


\section{CONCLUSION}

Double sided FSW in API X80 steel have been performed. Welds have been tested in accordance with ASTM E1820 and geometry dependent $\mathrm{J}_{\mathrm{Q}}$ and $\mathrm{CTOD}_{\mathrm{Q}}$ have been determined. Microhardness measurements from each weld have been used to understand how inhomogeneity of the SZ affects fracture toughness. Finally, relationships between fracture toughness and the process parameters of spindle speed and HI have been determined.

1. Fracture toughness in friction stir welded X80 exceeded both API Standard 1104 and DNVOS-F101 minimum CTOD requirements across all parameters investigated at room temperature. The minimum CTOD value was $0.243 \mathrm{~mm}$ was $143 \%$ and $62 \%$ higher than API Standard 1104 and DNV-OS-F101, respectively.

2. Due to stir zone inhomogeneity, within a single weld CTOD was found to be a function of crack location relative to the weld centerline. CTOD dropped by $50 \%$ with only a $300 \mu \mathrm{m}$ shift from retreating to advancing side of the weld centerline.

3. Fracture toughness increased linearly with decreases in both HI and spindle speed. Fracture toughness increased from 0.243 to $0.450 \mathrm{~mm}(85 \%)$ with a corresponding decrease in $\mathrm{HI}$ from 2600 to $1400 \mathrm{~J} / \mathrm{mm}$ (46\%) and spindle speed decrease from 725 to $300 \mathrm{RPM}(59 \%)$. 
4. The optimal parameters for fracture toughness in FSW X80 are a HI of $1400 \mathrm{~J} / \mathrm{mm}$ and spindle speed of $375 \mathrm{R}$ PM which yields a CTOD of $0.450 \mathrm{~mm}$, only $7 \%$ lower than the CTOD of the BM. 


\section{REFERENCES}

[1] Fairchild DP. Local Brittle Zones in Structural Welds. Welding Metallurgy of Structural Steels. Denver1987. p. 303-18.

[2] Fairchild D, Kumar A, Ford S, Nissley N, Ayer R, Jin. H, et al. Research Concerning the Friction Stir Welding of Linepipe Steels. Trends in Welding Research, Proceedings of the 8th International Conference2009. p. 371-80.

[3] Santos TFA, Hermenegildo TFC, Afonso CRM, Marinho RR, Paes MTP, Ramirez AJ. Fracture toughness of ISO 3183 X80M (API 5L X80) steel friction stir welds. Engineering Fracture Mechanics. 2010;77:2937-45.

[4] Rodriguez-Ibabe JM. The Role of Microstructure in Toughness Behavior of Microalloyed Steels. Materials Science Forum. 1998;284-286.

[5] Hertzberg RW. Deformation and fracture mechanics of engineering materials: J. Wiley \& Sons; 1996.

[6] Sampath K. An understanding of HSLA-65 plate steels. Journal of materials engineering and performance. 2006;15:32-40.

[7] Ozekcin A, Jin HW, Koo JY, Bangaru NV, Ayer R, Vaughn G, et al. A Microstructural Study of Friction Stir Welded Joints of Carbon Steels. Int J Offshore Polar. 2004;14:2848 .

[8] Hillenbrand H-G, Liessem A, Biermann K, Heckmann CJ, Schwinn V. Development of grade X120 pipe material for high pressure gas transportation lines. 4th International Conference on Pipeline Technology. Osten, Belgium2004.

[9] Bhadeshia H. Bainite in Steels: Transformations, Microsctructure and Properties. 2nd ed: Institute of Materials, 1 Carlton House Terrace, London, SW 1 Y 5 DB, UK; 2001.

[10] Rodrigues PCM, Pereloma EV, Santos DB. Mechanical properities of an HSLA bainitic steel subjected to controlled rolling with accelerated cooling. Materials Science and Engineering: A. 2000;283:136-43. 
[11] Kumar A, Kumar B, Datta G, Ranganath V. Effect of microstructure and grain size on the fracture toughness of a micro-alloyed steel. Materials Science and Engineering A. 2010;527:954-60.

[12] Robinson JN, Tuck CW. Relationship Between Microstructure and Fracture Toughness for a Low-Alloy Steel. Engineering Fracture Mechanics. 1972;4:377-92.

[13] Wang C, Wang M, Shi J, Hui W, Dong H. Effect of Microstructure Refinement on the Strength and Toughness of Low Alloy Martensitic Steel. Journal of Materials Science \& Technology. 2007;23:659-64.

[14] Chen JH, Wang GZ, Wang Q, Liu YG. Effects of Sizes of Ferrite Grains and Carbide Particles on Toughness of Notched and Precracked Specimens of Low-Alloy Steels. International Journal of Fracture. 2004;126:223-41.

[15] Miglin MT, Hirth JP, Rosenfield AR. Effects of Microstructure on Fracture Toughness of a High-Strength Low-Alloy Steel. Metallurgical Transactions A. 1983;14A:2055-61.

[16] Xu X, Su Y, Zhou W, Cai Q. Relationship Between M--A Constituent and Cleavage Fracture Behaviour of Granular Bainitic Weld Metal. Acta MetallSin(EnglEd) A. 1989;2:143-6.

[17] Shinohara Y, Nagata Y, Tsuru E, Hara T. Evaluation for Fracture Toughness in Welded X80 Pipes:Experimental Analysis on Mechanical Properties of HAZ. Twenty-first (2011) International Offshore and Polar Engineering Conference. Maui, Hawaii, USA: International Society of Offshore and Polar Engineers; 2011.

[18] Wiebe J, Scheller W, Bruns C, Schmidt T. Influence of Heat Input during GMAW on the Mechanical Properties of Seamless Line Pipe Steels up to X80. Twenty-first (2011) International Offshore and Polar Engineering Conference. Maui, Hawaii, USA: International Society of Offshore and Polar Engineers; 2011.

[19] Shi YW, Han ZX. Effect of Weld Thermal Cycle on Microstructure and Fracture Thoughness of Simulated Heat-Affected Zone For a 800 Mpa Grade High Strength Low Alloy Steel. Journal of Materials Processing Technology. 2008;207:30-9.

[20] Lee S, Kim BC, Kwon D. Correlation of Microstructure and Fracture Properties in Weld Heat-Affected Zones of Thermomechanically Controlled Processed Steels. Metallurgical Transactions A. 1992;23A:2803-16.

[21] Hehemann RF, Luhan VJ, Troiano AR. The Influence of Bainite on Mechanical Properties. ASM transactions quarterly. 1957;49:409-26.

[22] Fairchild DP. Fracture Toughness Testing of Weld Heat-Affected Zones in Structural Steel. Fatigue and Fracture Testing of Weldments. Sparks 1988. p. 117-41. 
[23] Johnson DR, Becker WT. Toughness of tempered upper and lower bainitic microstructures in a 4150 steel. Journal of Materials Engineering and Performance. 1993;2:255-363.

[24] Shome M. Effect of Heat-Input on Austenite Grain Size in the Heat-Affected Zone of HSLA-100 Steel. Materials Science and Engineering A. 2007;445-446:454-60.

[25] Shome M, Mohanty ON. Countinuous Cooling Transformation Diagrams Applicable to the Heat-Affected Zone of HSLA-80 and HSLA-100 Steels. Metallurgical and Materials Transactions A. 2006;37A:2159-68.

[26] Prasad K, Dwivedi DK. Some investigations on microstructure and mechanical properties of submerged arc welded HSLA steel joints. The International Journal of Advanced Manufacturing Technology. 2008;36:475-83.

[27] Bayley CJ, Mantei A. Influence of Weld Heat Input on the Fracture and Metallurgy of Hsla-65. Can Metall Quart. 2009;48:311-6.

[28] Shimamura J, Okatsu M, Ishikawa N, Nishimura K, Murakami Y, Tsuyama S, et al. Material Design Concept in Heavy Wall X100 High Strength Linepipe Steel. Twentyfirst (2011) International Offshore and Polar Engineering Conference. Maui, Hawaii, USA: International Journal of Offshore and Polar Engineering; 2011.

[29] Suarez JC, Molleda F, Gonzales R, Jimenez R. Correlation of Modified Crack-Tip Opening Distance with Heat Input to the Heat-Affected Zone of High-Strength Low-Alloy Steels. Theor Appl Fract Mec. 1994;21:17-22.

[30] Kulekci MK, Mendi F, Sevim I, Basturk O. Fracture Toughness of Friction Stir Welded Joints of AlCu4SiMg Aluminium Alloy. Metalurgija. 2005;44:209-13.

[31] Wei LY. Investigating Correlations of Microstructures, Mechanical Properties and FSW Process Variables in Friction Stir Welded High Strength Low Alloy 65 Steel [PhD Dissertation]. Provo2009.

[32] Cho HH, Kang SH, Kim SH, Oha KH, Kim HJ, Chang WS, et al. Microstructural evolution in friction stir welding of high-strength linepipe steel. Materials and Design. 2012;34:258-67.

[33] Lee Y, Kim JY, Lee JS, Kim KH, Koo JY, Kwon D. Using the instrumented indentation technique for stress characterization of friction stir-welded API X80 steel. Philosophical Magazine. 2006;86:5497-504.

[34] Haji H, Wynne BP, Palmiere EJ. A Microstructure Analysis of Friction Stir Welded HSLA65. 8th International Friction Stir Welding Symposium. Timmendorfer Strand, Germany2010.

[35] Wade M, Reynolds AP. Friction stir weld nugget temperature asymmetry. Science and Technology of Welding \& Joining. 2010;15:64-9. 
[36] Horschel JD. Mode One Fracture Toughness Testing Of Friction Stir Proccessed HSLA-65 [Masters Thesis]. Provo: Brigham Young University; 2008.

[37] Pew J. A Torque Based Weld Power Model for Friction Stir Welding [Masters Thesis]. Provo: Brigham Young University; 2006.

[38] ASTM. Standard Test Method for Measurement of Fracture Toughness. ASTM E1820 - 11 West Conshohocken, PA: ASTM International; 2001. 
APPENDIX A. CS4 TOOL DRAWING 


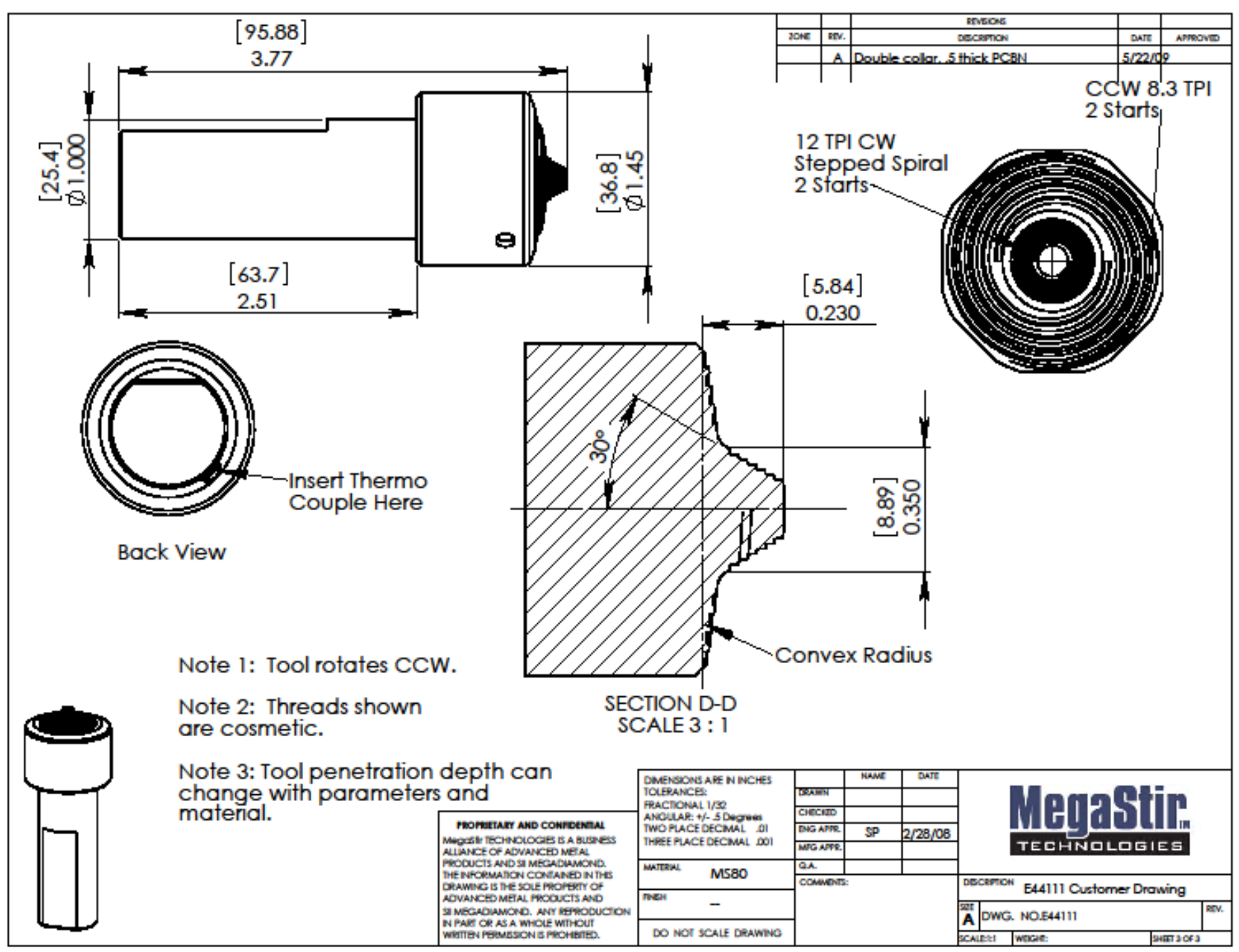

Figure A-4-1. CS4 Tool Drawing 
APPENDIX B. COMPACT TENSION SAMPLE DRAWING 


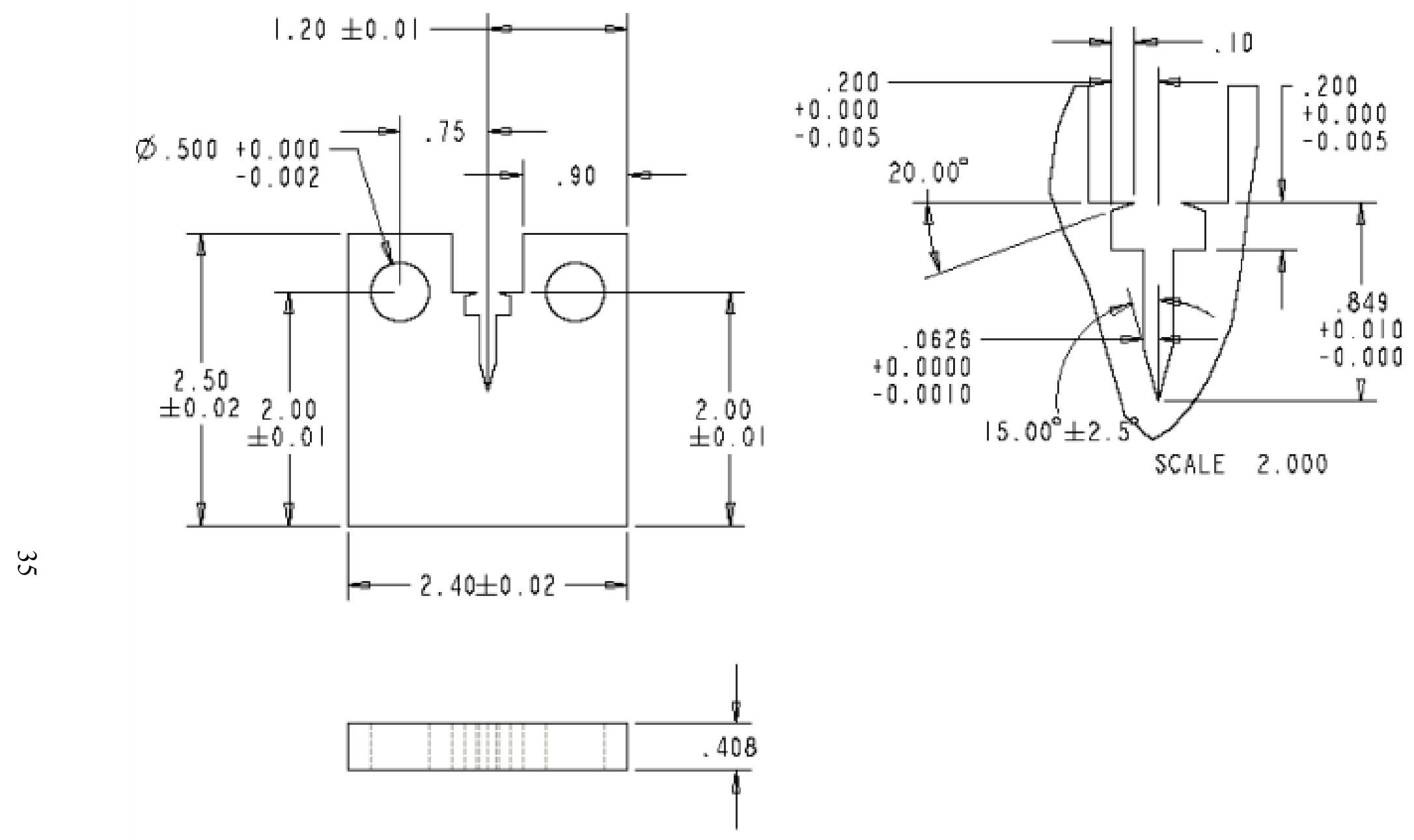

Part Name: $X 80$ CT Sample

Figure B-4-2. Compact Tension Sample Dimensions 
APPENDIX C. ASTM E1820 THICKNESS INDEPENDENT FRACTURE TOUGHNESS CRITERIA 
The ASTM E1820 criteria listed in the table below are required to qualify each sample as geometry independent toughness. However, no sample met all the criteria, therefore all toughness values are geometry dependent.

A brief explanation of the criteria will follow below. Criteria from ASTM E1820 appendix A deal with the calculation of a $\mathrm{J}_{\mathrm{Q}}$ value using the resistance curve procedure. Criteria A9.6.4 \#1 and \#2 deal with the necessity of having data points between the $.15, .5$, and $1.5 \mathrm{~mm}$ exclusion lines. A9.8.2.1 requires the calculated initial crack length to be within $0.01 \mathrm{~W}$ of the optically measured initial crack length, where $\mathrm{W}$ is the width of the CT sample. A9.8.2.2 requires a specific number of points to calculate the initial crack length and $\mathrm{J}_{\mathrm{Q}}$ as well as the curve fit to have a minimum $\mathrm{R}^{2}$ value greater than $96 \%$, which only one sample met.

Criteria in section 8 of ASTM E1820 deal with the testing procedure. Section 8.6.3.1 requires the three initial crack estimations to be $\pm .002 \mathrm{~W}$ of the mean. 8.6.3.2 requires more than 8 data points before the load reaches its maximum value.

Criteria from section 9 of ASTM E1820 deal with the uniformity of the optically measured crack front. Criteria 9.1.4.1 and 9.1.4.2 specify that none of the crack measurements differ from the mean by more than $5 \%$ of both the initial crack length and the final crack length respectively. Section 9.1.5.1 requires that none of the crack extension measurements be less than $50 \%$ of the average crack extension. 9.1.5.2 s pecifies how different from the actual crack extension the predicted crack extension can be. 
Table C-1. ASTM E1820 Thickness Independent Fracture Toughness Criteria

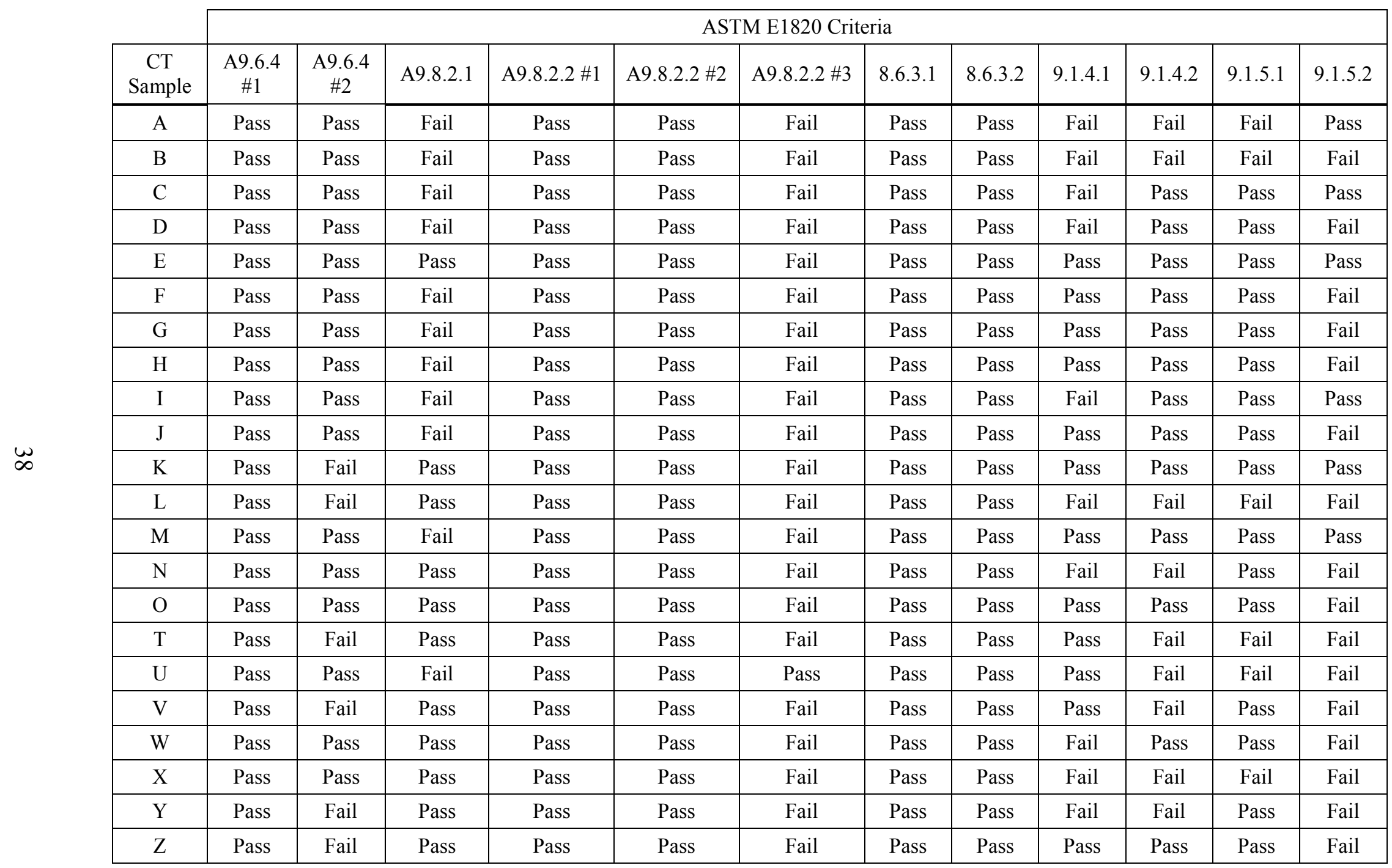


APPENDIX D. EXPLORED MICROSTRUCTURAL RELATIONSHIPS 
Many relationships were explored to see if they would correlate with lath and packet size. Below is a brief explanation of which relationships were tried and why they were not real relationships.

The four microstructural measurements (nugget center lath and packet size, centerline hardest area lath and packet size) were tested against the input parameters of spindle speed (SS) and $\mathrm{HI}$. The factors tested were $\mathrm{HI}, \mathrm{SS}, \mathrm{HI}^{2}, \mathrm{SS}^{2}$, and $\mathrm{HI}{ }^{*} \mathrm{SS}$. Using the minimum toughness in each weld, with welds 1 and 9 removed, all factors were found to have extremely low p-values. This means that the only way to fit the data was to have a model that was a high enough order polynomial to fit the noise in the data.

Previous authors found linear relationships between HI and microstructural changes [7, 31]. However, when linear relationships were tested one or both inputs were found to be insignificant and $\mathrm{R}^{2}$ values were well below $50 \%$, indicating a poor fit.

The minimum CTOD value for each weld was also used in an attempt to find a relationship between microstructure measurements and toughness. These tests resulted in extremely low $\mathrm{R}^{2}$ values for linear and quadratic fits. More importantly the attempted line fits had high p-values in the analysis of variance test, which indicates that was no significant factor in the proposed model. 